Journal of Geophysical Research: Solid Earth

\section{RESEARCH ARTICLE \\ 10.1002/2016JB013754 \\ Inelastic deformation during sill and laccolith emplacement: Insights from an analytic elastoplastic model}

Key Points:

- We present an analytical model

of igneous sill and laccolith emplacement accounting for

inelastic deformation at intrusion tips

- The size of the inelastic zone scales with the inverse of (1) the intrusion radius and (2) the square root of the magma overpressure

- Our model shows that the effect of the inelastic zone can be substantial for small intrusions, whereas it decreases with large intrusions

Supporting Information:

- Supporting Information S1

- Code S1

- Code S2

- Code S3

Correspondence to:

O. Galland,

olivier.galland@geo.uio.no

\section{Citation:}

Scheibert, J., O. Galland, and A. Hafver (2017), Inelastic deformation during sill and laccolith emplacement: Insights from an analytic elastoplastic model, J. Geophys. Res. Solid Earth, 122, doi:10.1002/2016JB013754.

Received 17 NOV 2016 Accepted 29 DEC 2016 Accepted article online 31 DEC 2016

O2016. American Geophysical Union. All Rights Reserved.

\author{
J. Scheibert ${ }^{1}\left(\mathbb{D}\right.$, O. Galland ${ }^{2}\left(\mathbb{D}\right.$, and A. Hafver ${ }^{2}$ \\ ${ }^{1}$ Laboratoire de Tribologie et Dynamique des Systèmes, UMR5513, CNRS/Ecole Centrale de Lyon/Univ Lyon/ENISE/ENTPE, \\ Ecully, France, ${ }^{2}$ Physics of Geological Processes, Department of Geosciences, University of Oslo, Norway
}

\begin{abstract}
Numerous geological observations evidence that inelastic deformation occurs during sills and laccoliths emplacement. However, most models of sill and laccolith emplacement neglect inelastic processes by assuming purely elastic deformation of the host rock. This assumption has never been tested so that the role of inelastic deformation on the growth dynamics of magma intrusions remains poorly understood. In this paper, we introduce the first analytical model of shallow sill and laccolith emplacement that accounts for elastoplastic deformation of the host rock. It considers the intrusion's overburden as a thin elastic bending plate attached to an elastic-perfectly plastic foundation. We find that, for geologically realistic values of the model parameters, the horizontal extent of the plastic zone $I_{p}$ is much smaller than the radius of the intrusion $a$. By modeling the quasi-static growth of a sill, we find that the ratio $I_{p} / a$ decreases during propagation, as $1 / \sqrt{a^{4} \Delta P}$, with $\Delta P$ the magma overpressure. The model also shows that the extent of the plastic zone decreases with the intrusion's depth, while it increases if the host rock is weaker. Comparison between our elastoplastic model and existing purely elastic models shows that plasticity can have a significant effect on intrusion propagation dynamics, with, e.g., up to a doubling of the overpressure necessary for the sill to grow. Our results suggest that plasticity effects might be small for large sills but conversely that they might be substantial for early sill propagation.
\end{abstract}

\section{Introduction}

Over the past few decades, geological field studies [Polteau et al., 2008; Galerne et al., 2011; Schofield et al., 2012] and seismic reflection data [Hansen et al., 2004; Planke et al., 2005; Hansen et al., 2008; Polteau et al., 2008; Galland et al., 2009; Galerne et al., 2011; Magee et al., 2014, 2016] have revealed the presence of voluminous igneous complexes in sedimentary basins worldwide. Igneous intrusions in these basins exhibit various shapes, from flat or saucer-shaped sills to laccoliths [Planke et al., 2005; Jackson et al., 2013]. It has been demonstrated that intrusive rocks and processes have major impacts on the thermal and structural evolutions of sedimentary basins [Petford and McCaffrey, 2003; Schutter, 2003]. Among others (1) sills provide heat that locally maturates the organic matter in the surrounding sediments [Svensen et al., 2004; Rodriguez Monreal et al., 2009; Aarnes et al., 2011], (2) sill emplacement may cause uplift and deformation of the host rock, forming broad domes, or forced folds, of their overlaying strata [Jackson and Pollard, 1990; Trude et al., 2003; Hansen and Cartwright, 2006; Jackson et al., 2013; Agirrezabala, 2015], and (3) damage induced by the emplacement of magma produces fractures in the host rock that enhance fluid flow [Delaney and Pollard, 1981; Meriaux et al., 1999; Chevallier et al., 2004; Senger et al., 2015].

Sills also represent significant parts of the plumbing systems of active volcanoes worldwide. Field studies have highlighted the presence of sills and laccoliths in volcanic complexes [e.g., Pasquare and Tibaldi, 2007; Burchardt, 2008]. Numerous geodetic surveys have also revealed the emplacement of sills, some of which resulting in eruptions, among others, in the Galápagos Islands [e.g., Amelung et al., 2000], Eyjafjallajökull volcano, Iceland [e.g., Pedersen and Sigmundsson, 2004, 2006; Sigmundsson et al., 2010], in the Afar region, Ethiopia [e.g., Nobile et al., 2012; Pagli et al., 2012], and Piton de la Fournaise volcano, Réunion Island [e.g., Chaput et al., 2014].

In sedimentary basins, existing theoretical and numerical models of sill and laccolith emplacement account for elastic host rock only. Classical models, as well as very recent ones, consider the sill overburden as an elastic thin plate clamped to a perfectly rigid basement [Pollard and Johnson, 1973; Jackson and Pollard, 1990; Scaillet et al., 1995; Kerr and Pollard, 1998; Goulty and Schofield, 2008; Bunger and Cruden, 2011; Michaut, 2011; 
Michaut and Manga, 2014; Thorey and Michaut, 2014; Michaut et al., 2016], and assume intrusion propagation to obey Linear Elastic Fracture Mechanics (LEFM) theory. Because these models are clamped, they only account for deformation above the intrusion, which is not realistic [Galland and Scheibert, 2013, and references therein]. To overcome this limitation, a more advanced mathematical formulation considers a thin elastic plate on top of a deformable elastic foundation [Kerr and Pollard, 1998; Galland and Scheibert, 2013]. The latter models produce realistic elastic deformation of sills overburden (see discussion by Agirrezabala [2015]); however, they are also limited to purely elastic propagation of the intrusions.

Rubin [1993] argues that the fracture toughness propagation criterion used in LEFM theory does not apply for intrusions deeper than a few hundred meters (i.e., for most sills and laccoliths). In addition, recent geological and geophysical observations show that some inelastic deformation accommodates sill and laccolith emplacement in sedimentary formations (Figure 1). At shallow levels, igneous sills often intrude into rocks that deform inelastically, such as soft shale formations [e.g., Planke et al., 2005; Jackson et al., 2013; Spacapan et al., 2016]. Pollard et al. [1975], Duffield et al. [1986], Schofield et al. [2012, 2014] and Spacapan et al. [2016] provide field evidence that inelastic deformation in the vicinity of intrusion tips might play a significant role in the emplacement of sills and dikes in soft rock formations. Such inelastic deformation involves, among others, joints and microfractures [Delaney and Pollard, 1981] and brittle and ductile faulting [Pollard, 1973; Pollard et al., 1975; Spacapan et al., 2016].

In active volcanoes, geodetic measurements are commonly interpreted using models that also consider purely elastic host rock [e.g., Mogi, 1958; Okada, 1985; Sun, 1969; Fialko et al., 2001], even if evidence of inelastic deformation are visible at the Earth surface. In addition, these models are static, i.e., they do not account for intrusion propagation, although seismological measurements evidence distributed inelastic failure of the host rock in the vicinity of propagating intrusions [Roman and Cashman, 2006; Daniels et al., 2012].

Despite such geological and geophysical evidences, inelastic deformation keeps being neglected in most models of sill and laccolith emplacement. A classic argument to justify this assumption is that inelastic deformations are restricted to zones that are very small compared to the size of the modeled intrusions, and so these deformations are likely to have a negligible effect [e.g., Pollard and Johnson, 1973; Kerr and Pollard, 1998; Bunger and Cruden, 2011]. This assumption, however, has not been tested, so that the real effect of inelastic deformation on intrusion propagation is currently unknown. This leads to the following questions: What is the relative contribution of inelastic versus elastic deformation of the host rock during sill and laccolith emplacement? What is the size of the inelastic zone at the tips of sills and laccoliths? To address these questions, in this paper, we develop and use a new elastoplastic theoretical model of sill and laccolith emplacement. Here plasticity will be taken as a first, mathematically tractable, example of inelastic process. Note that due to model assumptions discussed later on, we mostly focus on the emplacement of igneous intrusions in undeformed sedimentary basins.

The paper is structured as follows. In section 2, we build on the classic clamped elastic model of Pollard and Johnson [1973] and introduce a plastic zone at the intrusion's tip. Unfortunately, this simple model cannot be used to uniquely determine sill growth. Therefore, in section 3, we introduce a new elastoplastic model based on the recent model of Galland and Scheibert [2013] and use it to predict how the plastic zone evolves as a sill grows. In section 4, we discuss the geological implications of the model.

\section{The Clamped Plastic Model}

\subsection{Model Equations}

We consider the following system, sketched in Figure 2: an axisymmetric flat intrusion of radius $a$ lying under a linear elastic strata of thickness $h$, Young modulus $E$, Poisson ratio $v$, and mass density $\rho$. We assume that the intrusion is shallow $(a / h>5)$ so that the strata can be considered as a thin plate with a bending stiffness $D=\frac{E h^{3}}{12\left(1-v^{2}\right)}$. Above the intrusion (radial distance $r<a$ ), the plate is subjected to a radial pressure profile of the form $P=P_{0}-\left(P_{0}-P_{a}\right)(r / a)^{n}$, in which $P_{0}$ and $P_{a}$ are the pressure values at the center $(r=0)$ and periphery $(r=a)$ of the intrusion, respectively, and $n$ is an exponent that controls the shape of the pressure field [see Figure $2 d$ of Galland and Scheibert, 2013].

Just outside the intrusion $(r>a)$, there is an inelastic zone in which the stress borne by the interfacial material equals its yield stress $\sigma_{Y}$. This is different from the purely elastic fracture assumed in the classical clamped model, where the transition between the broken and nonbroken states of the interface layer is infinitely sharp. 

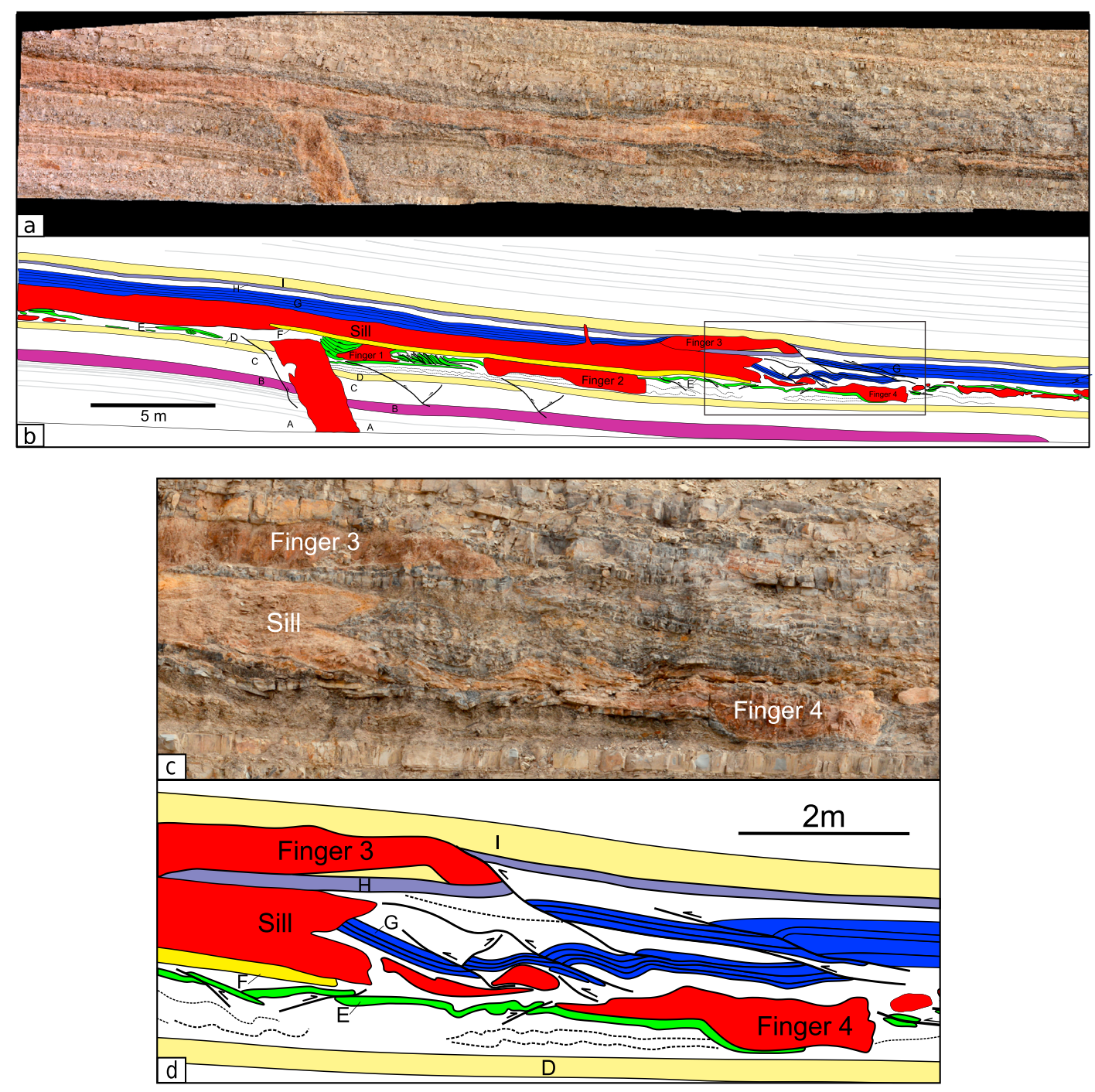

Figure 1. (a) Field orthorectified image and (b) interpreted drawing of outcrop exposing a sheet-like sill, magmatic fingers, and the associated structures in the shale-carbonate host rock, Cuesta del Chihuido, Mendoza Province, Argentina [Spacapan et al., 2016]. The box locates the (c) zoomed image and (d) associated interpreted drawing. The outcrop shows that the sill tip is round or blunt and that substantial inelastic deformation (brittle faulting of the carbonate layers and ductile flow of the shale layers) accommodates the emplacement and propagation of the sill. Detailed descriptions of the structures and associated mechanisms can be found in Spacapan et al. [2016].

Here we define a zone of finite size that accommodates the progressive breaking process. Field observations show that various inelastic deformation mechanisms are associated with igneous intrusion propagation: joints and microfractures [Delaney and Pollard, 1981], brittle and ductile faulting [e.g., Pollard, 1973; Pollard et al., 1975; Schofield et al., 2012; Spacapan et al., 2016], or secondary fluidization [Schofield et al., 2012; Jackson et al., 2013]. It is challenging to account for each individual mechanism; therefore, we apply a generic perfectly plastic rheological law in the inelastic zone, subsequently referred to as plastic zone. We define $r=b$ as the tip of the plastic zone, the length of which is thus $I_{p}=b-a$. Note that $b$ would be equal to $a\left(I_{p}=0\right)$ in the case of purely brittle behavior.

Outside the plastic zone, the plate is rigidly attached to the basement. At all points of the model, the plate is also submitted to the lithostatic stress $q_{0}=\rho g h$, with $g$ being the gravitational acceleration. In the following, we will define $\Delta P=P_{0}-q_{0}$ as the overpressure at the sill's center. Note that the basement is considered to be perfectly rigid. As sill expansion rates are much smaller than the speed of sound in the surrounding rocks and magma, we can neglect any inertial effect so that the model becomes quasi-static. 


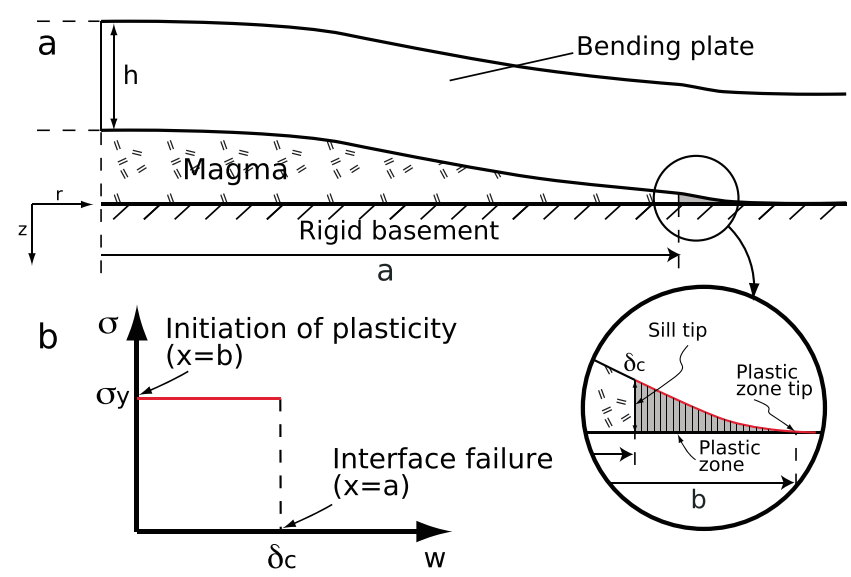

Figure 2. (a) Schematic drawing of the clamped plastic model. A plate of thickness $h$ is attached to a rigid foundation and is subject to the lithostatic stress $q_{0}=\rho g h$. An axisymmetric sill of radius $a$ applies a (possibly heterogeneous) pressure distribution $P(r)$ at the bottom of the plate and lifts it up. Between the tip of the sill $(x=a)$ and the clamped region (plastic zone tip; $x=b$ ), a cohesive crack tip of size $b-a$ defines a plastic zone. The failure of the interface along which the sill propagates is defined by a critical displacement $\delta_{c}$. (b) Schematic diagram representing the rigid-perfectly-plastic law used within the plastic zone illustrated in Figure 2a. Plasticity is here defined by a constant stress value $\sigma_{Y}$, i.e., the yield stress of the interface between the rigid foundation and the overlying elastic plate, when the plate displacement $w$ is between $w=0($ at $x=b)$ and $w=\delta_{c}($ at $x=a)$.

From thin plate theory, i.e., when the vertical displacements of the plate, $w$, remain small compared to the plate thickness $h$, we can write the equilibrium equations of the system as

$$
\begin{gathered}
D \Delta^{2} w=q_{0}-P_{0}+\left(P_{0}-P_{a}\right)(r / a)^{n}, \quad 0 \leq r \leq a, \\
D \Delta^{2} w=q_{0}+\sigma_{Y}, \quad a \leq r \leq b,
\end{gathered}
$$

where $\Delta^{2}$ is the bilaplacian operator. Note that positive displacements $w$ are defined downward, meaning that upward displacement of the plate would be negative.

In the following sections, we will refer to $w_{1}$ and $w_{p}$ for the displacements upon the sill $(0<r<a)$ and upon the plastic region $(a<r<b)$, respectively. Equation (1), when taken in axisymmetric form with abscissa $r$, has a general solution of the form [see Timoshenko and Woinowsky-Krieger, 1959, p. 54, equation (60)]:

$$
w_{1}=\frac{\left(q_{0}-P_{0}\right) r^{4}}{64 D}+\frac{C_{1} r^{2}}{4}+C_{2}+C_{9} \ln \left(\frac{r}{b}\right)+C_{10} r^{2} \ln \left(\frac{r}{b}\right)+\frac{\left(P_{0}-P_{a}\right) r^{n+4}}{D a^{n}(n+2)^{2}(n+4)^{2}}
$$

We set $C_{9}=C_{10}=0$ because the logarithms would lead to an unphysical displacement singularity at $r=0$. We are left with only two unknown constants, $C_{1}$ and $C_{2}$.

For $w_{p}$, we have to keep the contributions from the logarithms so that

$$
w_{p}=\frac{\left(q_{0}+\sigma_{Y}\right) r^{4}}{64 D}+\frac{C_{3} r^{2}}{4}+C_{4}+C_{5} \ln \left(\frac{r}{b}\right)+C_{6} r^{2} \ln \left(\frac{r}{b}\right)
$$

We are left with the following two equations, with $C_{1}$ to $C_{6}$ being six unknown constants:

$$
\begin{gathered}
w_{1}=\frac{\left(q_{0}-P_{0}\right) r^{4}}{64 D}+\frac{C_{1} r^{2}}{4}+C_{2}+\frac{\left(P_{0}-P_{a}\right) r^{n+4}}{D a^{n}(n+2)^{2}(n+4)^{2}}, \quad 0 \leq r \leq a \\
w_{p}=\frac{\left(q_{0}+\sigma_{Y}\right) r^{4}}{64 D}+\frac{C_{3} r^{2}}{4}+C_{4}+C_{5} \ln \left(\frac{r}{b}\right)+C_{6} r^{2} \ln \left(\frac{r}{b}\right), \quad a \leq r \leq b .
\end{gathered}
$$


Six boundary conditions are required to uniquely determine the six unknown coefficients in equations (5) and (6). Given that the plate is rigidly attached to the basement outside the plastic zone, the displacement and the first derivative of the displacement at $r=b$ must be 0 , i.e.,

$$
\begin{aligned}
& w_{p}(b)=0, \\
& w_{p}^{\prime}(b)=0,
\end{aligned}
$$

where the prime denotes derivation with respect to $r$.

Continuity of the displacement $w$ and its three first derivatives with respect to $r$ at $r=a$ yields four boundary conditions:

$$
\begin{aligned}
& w_{1}(a)=w_{p}(a), \\
& w_{1}^{\prime}(a)=w_{p}^{\prime}(a), \\
& w_{1}^{\prime \prime}(a)=w_{p}^{\prime \prime}(a), \\
& w_{1}^{\prime \prime \prime}(a)=w_{p}^{\prime \prime \prime}(a) .
\end{aligned}
$$

Substitution of equations (5) and (6) into equations (7) to (12) yields a linear system of six equations for the coefficients $C_{1}-C_{6}$. The system of equations is written out in full and solved in Appendix A. Note that we provide, as supporting information, both a Mathematica notebook (2016JB013569-sm01) with the analytical solutions for $C_{1}-C_{6}$ and a Matlab code (2016JB013569-sm02) which calculates $C_{1}-C_{6}$ for any set of parameters $\left(h, E, v, \rho, \sigma_{Y}, P_{a}, n, a, b\right.$, and $\left.P_{0}\right)$. Also note that for the rest of section 2, we will consider the particular case of a constant pressure distribution, $P_{a}=P_{0}$.

\subsection{Model Behavior}

We calculate a radial uplift profile, $-w(r)$ (the minus sign is due to our orientation convention for $w$ and ensures that uplift is counted positively), of the deforming plate of thickness $h$, using our clamped model with plastic zone, and compare it to the purely elastic clamped model of Pollard and Johnson [1973] using a set of geologically realistic parameters (Figure 3). The uplift calculated with our model is everywhere larger than that calculated with the model of Pollard and Johnson [1973] with the sill radius $r_{\text {sill }}=a$ (Figure 3). Conversely, the uplift calculated with our model is everywhere smaller than that calculated with the model of Pollard and Johnson [1973] with the sill radius $r_{\text {sill }}=b$ (Figure 3). This bracketing of our model can be readily understood by considering the uplift within the interval $a<r<b$ for the three models (Figure 3, right). In the plastic zone, the plate is allowed to deform somehow so that the uplift is higher than for the Pollard and Johnson [1973] model with $r_{\text {sill }}=a$, for which the uplift vanishes by definition beyond $r=a$. The difference with the Pollard and Johnson [1973] model with $r_{\text {sill }}=b$ is due to the fact that the magma pressure $P_{0}$ pushes the strata upward within the interval $a<r<b$, whereas, in the same interval of the plastic model, plasticity is resisting uplift.

We want to quantify the effect of the size $I_{p}$ of the plastic zone, which is the unknown primary quantity of interest in our model, on the system's behavior. Following Galland and Scheibert [2013], we scale the maximum uplift $-w_{\max }$ from our model by the maximum uplift from the clamped model $\frac{a^{4} \Delta P}{64 D}$ [Pollard and Johnson, 1973]. We plot in Figure 4 the results as a function of the dimensionless parameter $\epsilon=I_{p} / a$, which is the relative size of the plastic zone with respect to the radius of the sill. The advantage of this scaling is that $-\frac{64 D w_{\max }}{a^{4} \Delta P}=1$ when $\epsilon=0$. Figure 4 shows that, for small values of $\epsilon,-\frac{64 D w_{\max }}{a^{4} \Delta P}$ increases, until reaching a maximum, after which it decreases. This decrease at large values of $\epsilon$ is not physically meaningful: it corresponds to large values of $l_{p}$, which would induce strong downward pulling of the strata and thus negative uplift. We found that requiring the uplift to be everywhere positive happens to discard the $\epsilon$ values for which the curves in Figure 4 are decreasing. Therefore, we only consider the model behavior for small values of $\epsilon$. This is consistent with field observations suggesting that the sizes of plastic zones are much smaller than the radii of sills (i.e., $\epsilon$ is small).

Figure 4 shows that the obtained rescaled curves depend on $P, q_{0}$, and $\sigma_{Y}$ but not on $a, E$, and $v$. These dependencies can be understood from the Taylor expansion of $-w_{\max }$ for small $\epsilon$, provided in Appendix $B$, equation (B4). This expansion, truncated at third order (solid lines in Figure 4), is compared to the full model 

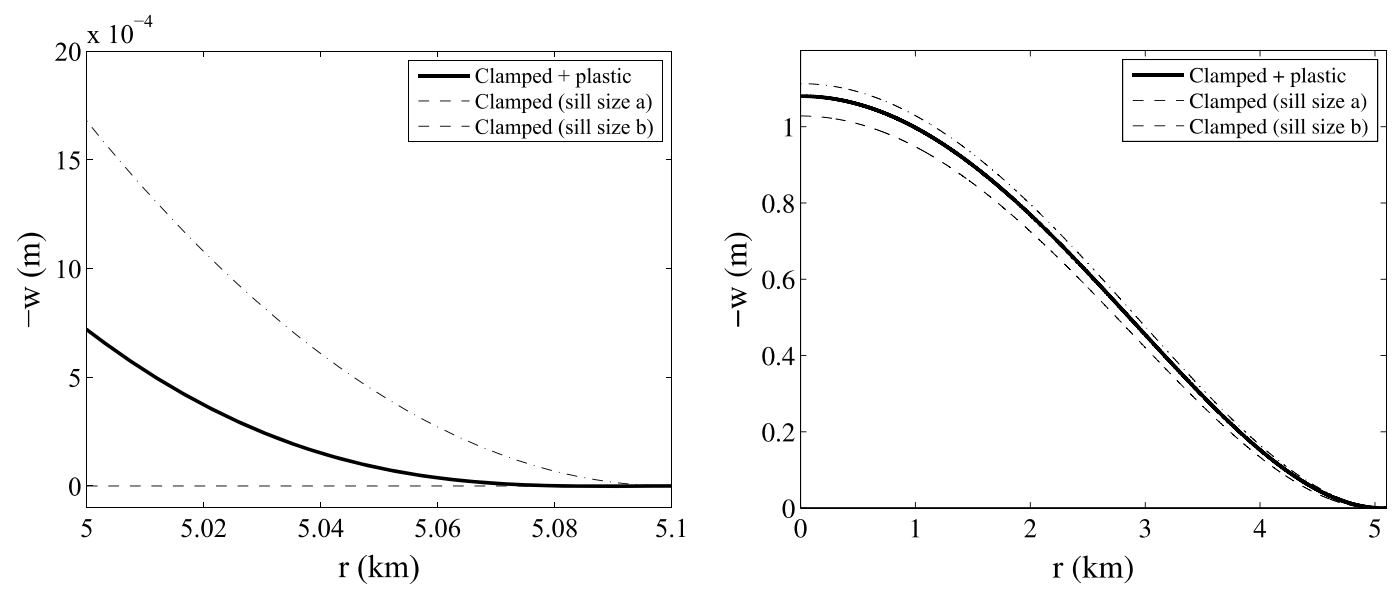

Figure 3. (left) Typical uplift profile $-w(r)$ for the clamped model with plasticity (solid line). Model parameters are the following: $h=1 \mathrm{~km}, E=10^{10} \mathrm{~Pa}, v=0.35, \rho=2500 \mathrm{~kg} \mathrm{~m}^{-3}, P_{0}=P_{a}=q_{0}+10^{5} \mathrm{~Pa}, \sigma_{Y}=5.10^{7} \mathrm{~Pa}$, $a=5 \mathrm{~km}$, and $b=5.1 \mathrm{~km}$. It is compared with two profiles calculated from the Pollard and Johnson [1973] model $\left(w_{P J}(r)=\frac{q_{0}-P_{0}}{64 D}\left(r^{2}-r_{\text {sill }}^{2}\right)^{2}\right)$, with the sill radius being either $r_{\text {sill }}=a$ (dashed line) or $r_{\text {sill }}=b$ (dash-dotted line). (right) Same curves, zoomed in on the plastic zone (between $a$ and $b$ ).

(dashed and dash-dotted lines in Figure 4). The truncated expansion seems to agree perfectly with the full model over the relevant range of $\epsilon$ values. It is interesting to note that the yield stress $\sigma_{Y}$ does not appear in the expansion before the third order (equation (B4)). As a matter of fact, the Taylor expansion of $-w_{\max }$ truncated at second order appears as a seemingly straight line in Figure 4 (dotted line), which shows that the third order is necessary to predict the correct shape of the evolution of the rescaled maximum uplift as a function of $\epsilon$. Thus, the third-order term is required to capture not only the effect of $\sigma_{Y}$ but also the individual effects of $P_{0}$ and $q_{0}$, when they are not combined into $\Delta P$. As expected intuitively, an increase of $\sigma_{Y}$ or $q_{0}$ decreases the maximum uplift, whereas an increase of $P_{0}$ increases it.

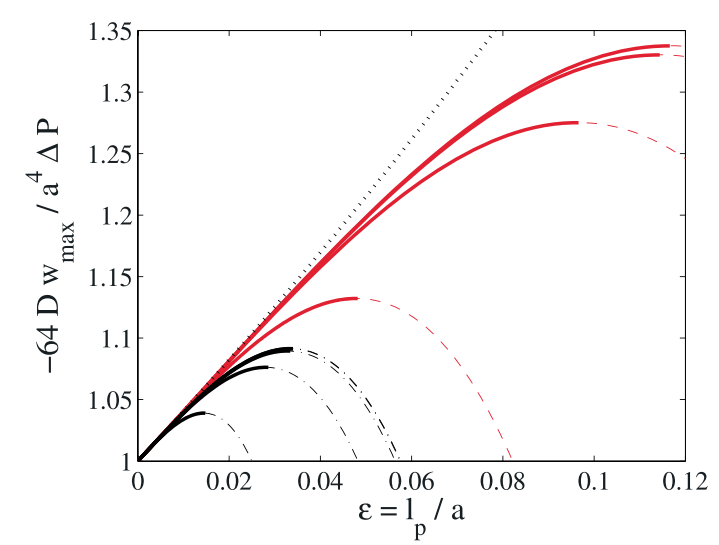

Figure 4. Rescaled maximum uplift $-\frac{64 D w_{\max }}{\Delta P a^{4}}$ as a function of the rescaled length of the plastic zone $\epsilon=\frac{l_{p}}{a}=\frac{b-a}{a}$. Solid lines: results of the clamped plastic model. Only values of $\epsilon$ such that the uplift is everywhere positive on $r<b$ are shown. Dotted line: Taylor expansions of the model result $-\frac{64 D w_{\max }}{\Delta P a^{4}}$ for small $\epsilon$ (see Appendix B, equation (B4)), truncated at second order. Dashed and dash-dotted lines: Taylor expansions (equation (B4)), truncated at third order. Red: $\Delta P=10^{6} \mathrm{~Pa}$. Black: $\Delta P=10^{5} \mathrm{~Pa}$. For each value of $\Delta P$, four values of $\sigma_{Y}$ are used. From top to bottom: $\sigma_{Y}=10^{i} \mathrm{~Pa}$, with $i$ from 5 to 8 . Other model parameters are the following: $h=1 \mathrm{~km}, E=10^{10} \mathrm{~Pa}, v=0.35, \rho=2500 \mathrm{~kg} \mathrm{~m}^{-3}$, and $a=5 \mathrm{~km}$.

\subsection{Size of the Plastic Zone}

Given that most theoretical models of sill and laccolith emplacement are purely elastic, none of them is able to predict the size of a plastic zone at intrusion tips. In order to derive a simple expression of the size of the plastic zone, we use the Taylor expansion of the uplift at the intrusion tip $\left(w_{1}(a)\right)$ for small $\epsilon$ (equation (B6)) and combine it with a classic propagation criterion, $w_{1}(a)=\delta_{c^{\prime}}$ based on a critical vertical displacement $\delta_{c}$ commonly used with cohesive zone formulations [see, e.g., Dugdale, 1960; Barenblatt, 1962; Chen et al., 2009]:

$$
\begin{aligned}
\delta_{c} \approx & \frac{a^{4} \epsilon^{2}\left(q_{0}-P_{0}\right)}{16 D}+\frac{3 a^{4} \epsilon^{3}\left(q_{0}-P_{0}\right)}{48 D} \\
& +\frac{a^{4} \epsilon^{4}\left(7 P_{0}+8 \sigma_{Y}+q_{0}\right)}{64 D} .
\end{aligned}
$$

This critical displacement (here $\delta_{c}<0$ ) is a material property and imposes a physical boundary condition $w_{1}(a)=\delta_{c}$ at $r=a$, 
which is valid at the onset of propagation. Keeping only the second-order term of $\epsilon$ in equation (13), the latter equation leads to a simple approximate expression of the dimensionless size of the plastic zone $\epsilon$ as a function of the model parameters and $\delta_{c}$ :

$$
\epsilon \approx \sqrt{\frac{16 \delta_{c} D}{a^{4} \Delta P}}
$$

This simple expression shows that the size $\epsilon$ of the plastic zone scales as $1 / a^{2}$ : the longer the sill, the smaller the plastic zone. This suggests that the growth of a sill is accompanied by a decrease in the size of the plastic zone. Equation (14) also highlights that $\epsilon$ scales as $1 / \sqrt{\Delta P}$, meaning that the plastic zone also shrinks when the overpressure increases. Conversely, equation (14) shows that $\epsilon$ scales as $\sqrt{\delta_{c}}$ and $\sqrt{D}$, which suggests that the plastic zone is larger when the critical displacement for failure $\delta_{c}$ increases and when the overburden is very stiff and/or when the intrusion is deep.

\subsection{Posedness of Sill Propagation}

Equation (14) gives a simple relationship between the size of the plastic zone $\epsilon$, the propagation criterion $\delta_{c^{\prime}}$ and the variable model parameters $a$ and $\Delta P$. However, in reality, during the propagation of a sill these parameters are interdependent and not prescribed a priori [Murdoch, 2002; Galland et al., 2009; Rivalta, 2010; Galland and Scheibert, 2013]. Therefore, constraining the dynamics of the plastic zone during sill propagation requires a mathematical formulation to predict the coupled dynamics of $a$ and $\Delta P$ in addition to that of $\epsilon$.

The models of Murdoch [2002], Bunger and Cruden [2011], Michaut [2011], and Galland and Scheibert [2013] show that the use of relevant boundary conditions is necessary to calculate the evolution of the radius of, and the overpressure inside, a growing sill. Typical boundary conditions used are (1) a propagation criterion and (2) the time evolution of the volume V of the sill [Bunger and Cruden, 2011; Galland and Scheibert, 2013].

In our model with a plastic zone, as mentioned above, the propagation criterion is a critical displacement at the intrusion tip, i.e.,

$$
\delta_{c}=w_{1}(a)=\frac{\left(q_{0}-P_{0}\right) a^{4}}{64 D}+\frac{C_{1} a^{2}}{4}+C_{2}
$$

using equation (B5).

Integrating the uplift over the projected area of the sill, the volume $V$ of the sill is easily calculated in cylindrical coordinates [Galland and Scheibert, 2013]:

$$
V=-2 \pi \int_{0}^{a} r w_{1}(r) \mathrm{d} r=-2 \pi\left(\frac{\left(q_{0}-P_{0}\right) a^{6}}{384 D}+\frac{C_{1} a^{4}}{16}+\frac{C_{2} a^{2}}{2}\right) .
$$

In equations (15) and (16), $C_{1}$ and $C_{2}$ are complicated functions of $\Delta P, a$, and $b$; hence, $V$ and $\delta_{c}$ are also nontrivial functions of $\Delta P, a$, and $b$. Thus, the mathematical problem has only two equations (equations (15) and (16)) for three unknowns $(a, b$, and $\Delta P)$ and therefore has no unique solution. Consequently, the clamped model with a plastic zone cannot be used to calculate the dynamics of the plastic zone during the growth of a sill, as already discussed by Kerr and Pollard [1998] and Galland and Scheibert [2013]. In the following section, we demonstrate that introducing an elastic foundation, as described by Kerr and Pollard [1998] and Galland and Scheibert [2013], is sufficient to solve the dynamics of the plastic zone at the tip of a growing sill.

\section{The Model With Elastoplastic Foundation}

\subsection{Model Formulation}

We consider again the same system as described in section 2 but with one key difference (Figure 5): Instead of clamping the plate onto the rigid basement at $r>b$, we now assume that the plate is lying over an elastic-perfectly plastic foundation of elastic modulus $k$ and of yield stress $\sigma_{Y}$. The new equilibrium equations of the system are

$$
\begin{gathered}
D \Delta^{2} w=q_{0}-P_{0}+\left(P_{0}-P_{a}\right)(r / a)^{n}, \quad 0 \leq r \leq a, \\
D \Delta^{2} w=q_{0}+\sigma_{Y}, \quad a \leq r \leq b, \\
D \Delta^{2} w+k w=q_{0}, \quad r \geq b,
\end{gathered}
$$




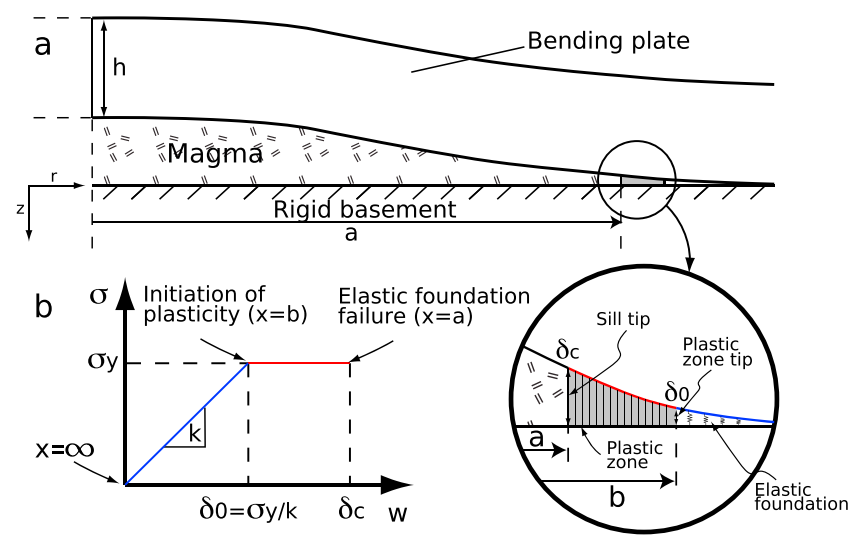

Figure 5. (a) Schematic drawing of the elastoplastic model developed in this paper (modified after Galland and Scheibert [2013]). A plate of thickness $h$ is attached to an elastic foundation of stiffness $k$ and is subject to the lithostatic stress $q_{0}$. The sill is axisymmetric with radius $a$, and a (possibly heterogeneous) pressure distribution $P(r)$ is applied at the bottom of the plate and lifts it up. Similarly to the model of Galland and Scheibert [2013], displacement is allowed outside the intrusion due to the elastic foundation. Here a plastic zone is confined between (1) the location of plasticity initiation, defined from a critical displacement $\delta_{0}=\frac{\sigma_{Y}}{k}$, and (2) the material crack tip, defined from a critical displacement $\delta_{c}$ dictating the failure limit of the host rock. (b) Schematic diagram representing the elastic-perfectly plastic law outside the intrusion. For small displacement $w<\delta_{0}$, deformation is elastic and governed by the stiffness of the elastic foundation. Displacements $\delta_{0}<w<\delta_{c}$, define the plastic zone, in which the stress is at a constant value, i.e., at yield stress $\sigma_{Y}$. For displacements $w>\delta_{c}$, the host rock has failed and is replaced by the overpressurized magma.

(plasticity of the foundation occurs between $a$ and $b$ ). Again, positive displacements $w$ are defined downward so that upward displacement of the plate is counted negatively.

In the case $a=b$ this model reduces to the previous model by Galland and Scheibert [2013]. In order to check if the present model is relevant, one may use the previous model of Galland and Scheibert [2013] to calculate $w(a)$ : if $-w(a)>\frac{\sigma_{Y}}{k}$, then plasticity occurs, and $b>a$ and the current model has to be used; otherwise, the model of Galland and Scheibert [2013] is sufficient.

In the following sections, we will refer to $w_{1}, w_{p}$, and $w_{2}$ for the displacements upon the sill $(0<r<a)$, upon the plastic region $(a<r<b)$ and outside the plastic region $(b<r)$, respectively. Equation (17), when taken in axisymmetric form with abscissa $r$, has a general solution of the form [see Timoshenko and Woinowsky-Krieger, 1959 , p. 54, equation (60)]:

$$
w_{1}=\frac{\left(q_{0}-P_{0}\right) r^{4}}{64 D}+\frac{C_{1} r^{2}}{4}+C_{2}+C_{9} \ln \left(\frac{r}{a}\right)+C_{10} r^{2} \ln \left(\frac{r}{a}\right)+\frac{\left(P_{0}-P_{a}\right) r^{n+4}}{D a^{n}(n+2)^{2}(n+4)^{2}}
$$

We set $C_{9}=C_{10}=0$ because the logarithms would lead to a displacement singularity at $r=0$. We are left with only two unknown constants $C_{1}$ and $C_{2}$.

For $w_{p}$, we have to keep the contributions from the logarithms so that

$$
w_{p}=\frac{\left(q_{0}+\sigma_{Y}\right) r^{4}}{64 D}+\frac{C_{3} r^{2}}{4}+C_{4}+C_{5} \ln \left(\frac{r}{a}\right)+C_{6} r^{2} \ln \left(\frac{r}{a}\right)
$$

Note that the constant in the denominator within the logarithms can be chosen arbitrarily. For convenience, we use one of the length scales in the model, $a$.

The general solution of equation (19), when the right-hand side is 0 , and when taken in axisymmetric form, is provided by [see Timoshenko and Woinowsky-Krieger, 1959, p. 266, equation (h)]

$$
w_{2}=C_{7} \operatorname{kei}_{0}(x)+C_{8} k r_{0}(x)+C_{11} \operatorname{ber}_{0}(x)+C_{12} b e i_{0}(x)
$$

with $x=\frac{r}{l_{e}} ; l_{e}=\sqrt[4]{\frac{D}{k}} ;$ and $b e r_{v}$, bei $_{v}, k_{v}$, and $k e i_{v}$ are Kelvin functions [Timoshenko and Woinowsky-Krieger, 1959]. We can set $C_{11}$ and $C_{12}$ to 0 because $\lim _{r \rightarrow \infty}$ ber $_{0}(r)=\infty$ and $\lim _{r \rightarrow \infty}$ bei $_{0}(r)=\infty$, which would yield unphysical infinite displacements far from the sill. Equation (19) also has a constant solution, $w_{0}=q_{0} / k$, which 
must be added to equation (22) to obtain the complete solution. Note that this term corresponds to the effect of the weight of the plate on the elastic foundation [Galland and Scheibert, 2013].

We are left with the following three equations, with $C_{1}$ to $C_{8}$ being eight unknown coefficients:

$$
\begin{gathered}
w_{1}=\frac{\left(q_{0}-P_{0}\right) r^{4}}{64 D}+\frac{C_{1} r^{2}}{4}+C_{2}+\frac{\left(P_{0}-P_{a}\right) r^{n+4}}{D a^{n}(n+2)^{2}(n+4)^{2}}, \quad 0 \leq r \leq a, \\
w_{p}=\frac{\left(q_{0}+\sigma_{Y}\right) r^{4}}{64 D}+\frac{C_{3} r^{2}}{4}+C_{4}+C_{5} \ln \left(\frac{r}{a}\right)+C_{6} r^{2} \ln \left(\frac{r}{a}\right), \quad a \leq r \leq b, \\
w_{2}=C_{7} k e i_{0}\left(\frac{r}{l_{e}}\right)+C_{8} k e r_{0}\left(\frac{r}{l_{e}}\right)+\frac{q_{0}}{k}, \quad r \geq b .
\end{gathered}
$$

To solve for the unknown coefficients, we need eight equations, which we obtain by requiring continuity of the displacement $w$ and its three first derivatives with respect to $r$ at $r=a$ and at $r=b$ :

$$
\begin{aligned}
& w_{1}(a)=w_{p}(a), \\
& w_{1}^{\prime}(a)=w_{p}^{\prime}(a), \\
& w_{1}^{\prime \prime}(a)=w_{p}^{\prime \prime}(a), \\
& w_{1}^{\prime \prime \prime}(a)=w_{p}^{\prime \prime \prime}(a) \\
& w_{p}(b)=w_{2}(b), \\
& w_{p}^{\prime}(b)=w_{2}^{\prime}(b), \\
& w_{p}^{\prime \prime}(b)=w_{2}^{\prime \prime}(b), \\
& w_{p}^{\prime \prime \prime}(b)=w_{2}^{\prime \prime \prime}(b) .
\end{aligned}
$$

Inserting equations (23)-(25) in (26)-(33), one obtains a set of eight linear equations for the coefficients $C_{1}-C_{8}$, which may be expressed in matrix vector form and solved by matrix inversion, as detailed in Appendix $C$. The analytical solutions for the coefficients are complicated but can be found in the Mathematica notebook (2016JB013569-sm01) provided as supporting information.

Replacing the values of $C_{1}$ to $C_{8}$ in equations (23)-(25) provides the radial profile of vertical displacement induced by a sill for any set of system parameters $\left(h, E, v, \rho, k, P_{a}, \sigma_{Y}\right.$, and $\left.n\right)$ and for any set of control parameters $\left(a, b\right.$, and $\left.P_{0}\right)$ (Figure 6). Note that we provide as supporting information a Matlab code (2016JB013569-sm03) which calculates $C_{1}-C_{8}$ for any set of parameters. Also, note that for the rest of section 3 , we will consider the particular case of a constant pressure distribution, $P_{a}=P_{0}$.

We emphasize that there are four length scales in the model: $h, l_{e^{\prime}} a$, and $I_{p}=b-a$. The thickness $h$ of the elastic strata is a parameter related to the geometry of the intrusion. The elastic length $I_{e}=\sqrt[4]{\frac{D}{k}}$ is an intrinsic length scale of the model, which represents the lateral distance, beyond the plastic zone periphery, over which significant displacements are found [Galland and Scheibert, 2013]. Note that $h$ is involved in the value of $l_{e^{\prime}}$ via $D$.

Our model is based on equations (17)-(19), which are only valid when $a / h \gg 1$. In the following, we will therefore only consider values of $a$ such that $a / h>5$, with 5 being an arbitrarily chosen limit for the validity of the thin plate formulation, already used by, e.g., Pollard and Johnson [1973], Bunger and Cruden [2011], and Galland and Scheibert [2013]. 

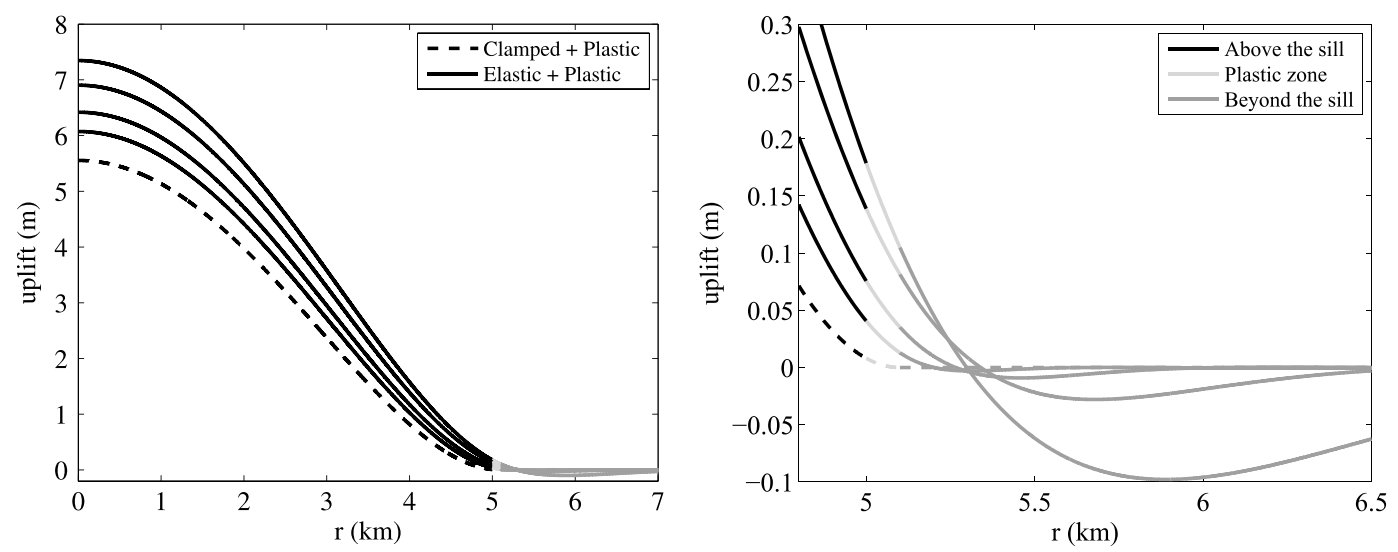

Figure 6. (left) Typical uplift profiles $-w_{i}(r)$ for the elastoplastic model (solid lines). Model parameters are the following: $h=1 \mathrm{~km}, E=10^{10} \mathrm{~Pa}, v=0.35, \rho=2500 \mathrm{~kg} \mathrm{~m}^{-3}, P_{0}=P_{a}=q 0+5.10^{5} \mathrm{~Pa}, \sigma_{Y}=10^{6} \mathrm{~Pa}, a=5 \mathrm{~km}$, and $b=5.1 \mathrm{~km}$, $k=10^{i} \mathrm{~Pa} \mathrm{~m}^{-1}$ with $i$ from 7 to 10 (from top to bottom, respectively). These profiles are compared with the corresponding clamped plastic profile, displayed with a dashed line. (right) The same curves, zoomed in at the vicinity of the plastic zone $(a<r<b)$.

Note that before the intrusion forms, the weight of the plate already pushes down on the elastic foundation so that there is already a homogeneous displacement $w_{0}=\frac{q_{0}}{k}$. We will consider this equilibrium state as the initial condition when the intrusion starts forming. Consequently, in order to calculate the displacement due to the intrusion, one needs to calculate the differential displacement $w_{i}=w-w_{0}=w-w(r \rightarrow \infty)$. For practical reasons, in the figures of the next sections, we plot the uplift induced by the emplacement of the intrusion, i.e., $-w_{i}$ (again, the minus sign is due to our orientation convention and ensures that uplift is counted positively).

The parameter $k$ has to be interpreted as the vertical stiffness of the weak layer along which the sill propagates. An extensive discussion of its physical meaning and relationship with the mechanical properties of the weak layer, as well as the range of geologically relevant values of $k$ are provided in Galland and Scheibert [2013]. Those values were obtained considering weak layers of minimal thickness $1 \mathrm{~m}$. Here, based on field observations showing thicknesses down to $10 \mathrm{~cm}$, we will allow for $k$ up to $10^{10} \mathrm{~Pa} \mathrm{~m}^{-1}$. In practice,

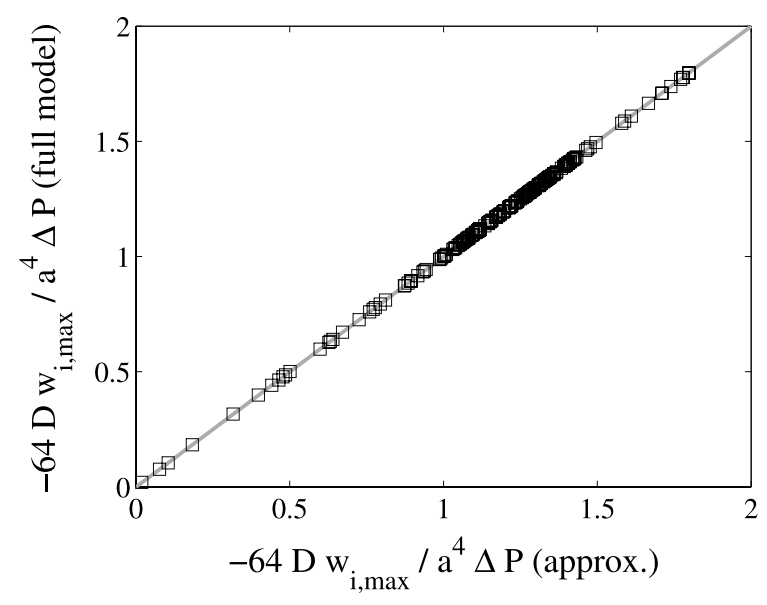

Figure 7. Rescaled maximum uplift in the full elastoplastic model, as a function of the rescaled approximate maximum uplift given by equation (D3). Squares are data points for the following sets of parameters: $h=1 \mathrm{~km} ; E=10^{10} \mathrm{~Pa} ; v=0.35 ; \rho=2500 \mathrm{~kg} \mathrm{~m}^{-3}$; $a=5 \mathrm{~km} ; P_{0}=P_{a}=q_{0}+10^{5}$ or $10^{6} \mathrm{~Pa} ; \sigma_{Y}=10^{i} \mathrm{~Pa}$ with $i=5$, 6 , or 7 ; and $k=10^{i} \mathrm{~Pa} \mathrm{~m}^{-1}$ with $i$ from 7 to 10 . For each set of parameters, $b$ takes 9 values such that the maximum uplift is never negative. Solid gray line: line of slope 1 passing through the origin. the smallest values of $k$ can, in the current model, lead to unrealistic negative uplift when the yield stress $\sigma_{Y}$ is large. As a consequence, we restricted ourselves to the range $k \in\left[10^{7}-10^{10}\right] \mathrm{Pa} \mathrm{m}^{-1}$.

\subsection{Model Behavior}

In this section, we investigate the behavior of the elastoplastic model and compare it to the clamped plastic model described in section 2. Figure 6 shows, for geologically realistic parameters, typical radial uplift profiles for the elastoplastic model. As described by Galland and Scheibert [2013], the uplift decreases as the stiffness of the elastic foundation increases, and the profiles converge toward the one predicted by the clamped plastic model when the stiffness approaches infinity. The uplift outside the plastic zone is now nonzero, which is expected with an elastic foundation: similarly to the model of Galland and Scheibert [2013], it shows a positive uplift close to the sill's tip and a negative 


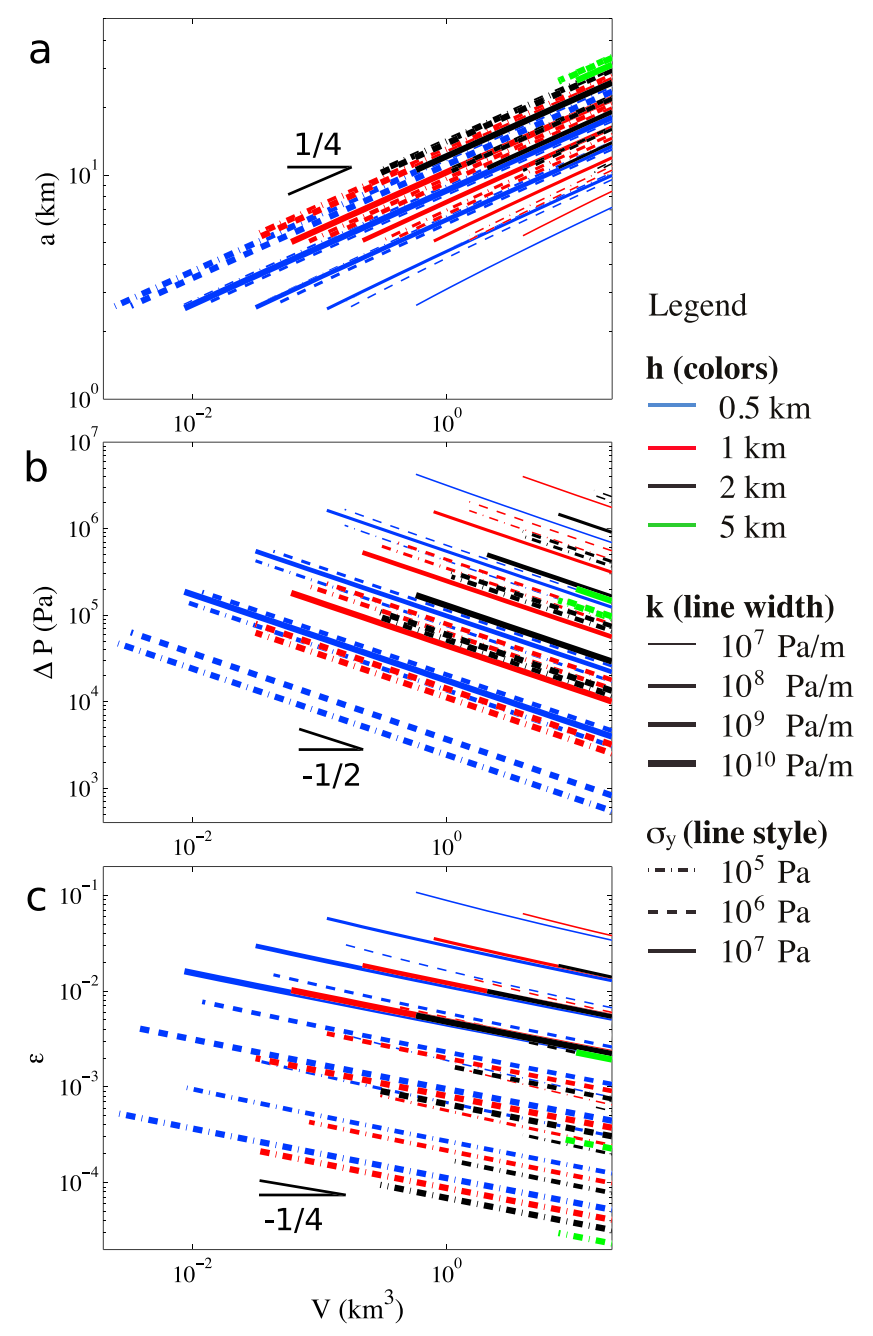

Figure 8. Plots of (a) the radius (a) of the sill, (b) the magma overpressure $(\Delta P)$, and (c) the size of the plastic zone $(\epsilon)$, as a function of the volume $V$ of a sill during its propagation, for various values of $h, k$, and $\sigma_{Y}$. Model parameters used are the following: $h=0.5 \mathrm{~km}$ (blue), $h=1 \mathrm{~km}$ (red), $h=2 \mathrm{~km}$ (black), $h=5 \mathrm{~km}$ (green), $k=10^{7} \mathrm{~Pa} \mathrm{~m}^{-1}$ (thinnest line), $k=10^{8} \mathrm{~Pa} \mathrm{~m}^{-1}$ (second thinnest line), $k=10^{9} \mathrm{~Pa} \mathrm{~m}^{-1}$ (second thickest line), $k=10^{10} \mathrm{~Pa} \mathrm{~m}^{-1}$ (thickest line), $\sigma_{Y}=10^{5} \mathrm{~Pa}$ (dash-dotted line), $\sigma_{Y}=10^{6} \mathrm{~Pa}$ (dashed line), and $\sigma_{Y}=10^{7} \mathrm{~Pa}$ (solid line). Here $\delta_{c}=5 \delta_{0}$, where $\delta_{0}=-\sigma_{Y} / \mathrm{k}$.

rebound at larger distances (Figure 6, right). Note that here the uplift at the sill's tip $(r=a)$ is controlled not only by the compliance of the elastic foundation but also by the allowed plastic deformation.

Although the full analytic solution of the elastoplastic model is complex, we managed to find a simple approximate analytical solution for the maximum uplift, $-w_{i, \max }$, which is given in equation (D3) in Appendix D. The approximation consists in replacing the Kelvin functions in equation (22) by their asymptotic forms for large values of their argument $r / I_{e}$. Note that this approximation was previously used in Galland and Scheibert [2013]. Figure 7 shows, for 216 different sets of geologically realistic parameters, that the prediction of the approximate maximum uplift captures perfectly the behavior of the full model. Equation (D3) can thus be used, for all practical purposes, as an excellent estimate of the maximum uplift $\left(-w_{i, \text { max }}\right)$ in the model as a function of system and control parameters.

\subsection{Modeling Sill Propagation}

We adopt here a similar approach to that described by Galland and Scheibert [2013] and in section 2.4. Instead of treating $a, b$, and $\Delta P$ as model input parameters, we define three boundary conditions in order to calculate these three quantities during the propagation of a sill. In many laboratory models [Murdoch, 2002; Bunger, 2005; Galland et al., 2009; Galland, 2012; Galland et al., 2014] and theoretical/ 


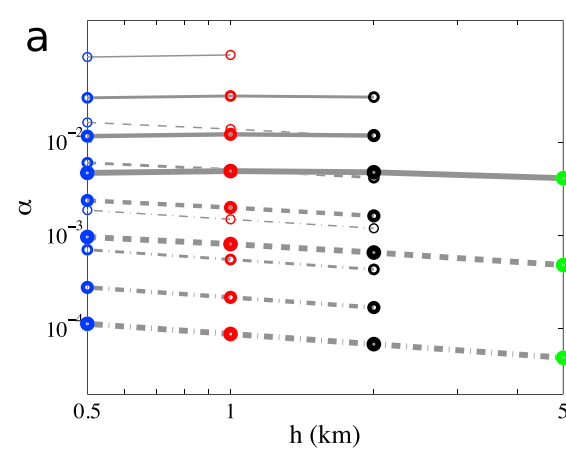

b
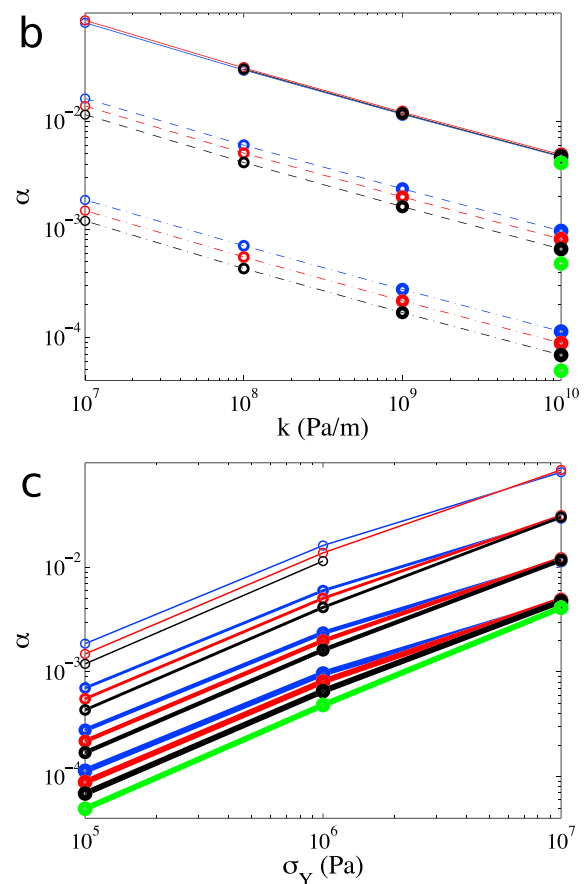

Legend

h (colors)

-o $0.5 \mathrm{~km}$

$-\theta-1 \mathrm{~km}$

$-2 \mathrm{~km}$

$-0-5 \mathrm{~km}$

$k$ (line width)

- $10^{7} \mathrm{~Pa} / \mathrm{m}$

$\rightarrow 10^{8} \mathrm{~Pa} / \mathrm{m}$

- $10^{9} \mathrm{~Pa} / \mathrm{m}$

- $10^{10} \mathrm{~Pa} / \mathrm{m}$

$\sigma_{\mathrm{y}}($ line style)

... $10^{5} \mathrm{~Pa}$

- - $10^{6} \mathrm{~Pa}$

Figure 9. Plots of $\alpha$, defined as $\epsilon=\alpha V^{-\frac{1}{4}}$ and calculated from data plotted in Figure 8c, as functions of (a) the depth (h), (b) the stiffness of the elastic foundation $(k)$, and (c) the yield stress of the elastic foundation $\left(\sigma_{Y}\right)$. Each curve of each plot considers only one variable parameter. Model parameters vary as follows: $h=0.5 \mathrm{~km}$ (blue), $h=1 \mathrm{~km}$ (red), $h=2 \mathrm{~km}$ (black), $h=5 \mathrm{~km}$ (green), $k=10^{7} \mathrm{~Pa} \mathrm{~m}^{-1}$ (thinnest line), $k=10^{8} \mathrm{~Pa} \mathrm{~m}^{-1}$ (second thinnest line), $k=10^{9} \mathrm{~Pa} \mathrm{~m}^{-1}$ (second thickest line), $k=10^{10} \mathrm{~Pa} \mathrm{~m}^{-1}$ (thickest line), $\sigma_{Y}=10^{5} \mathrm{~Pa}$ (dash-dotted line), $\sigma_{Y}=10^{6} \mathrm{~Pa}$ (dashed line), and $\sigma_{Y}=10^{7} \mathrm{~Pa}$ (solid line). Here $\delta_{c}=5 \delta_{0}$, where $\delta_{0}=-\sigma_{Y} / k$.

numerical models [Murdoch, 2002; Malthe-Sørenssen et al., 2004; Bunger and Cruden, 2011; Galland and Scheibert, 2013], the growth of a sill is imposed by a constant influx rate $Q$, such that the volume of the sill at any time $t$ is known as $V(t)=Q t$. The volume of the sill, given by $V=-2 \pi \int_{0}^{a} r w_{i}(r) \mathrm{d} r$, can thus be used as a boundary condition.

Figure 5 highlights that in our elastoplastic model, both sides of the plastic zone are imposed by a critical displacement. The critical displacement $\delta_{0}$ at the external tip of the plastic zone $(r=b)$ marks the initiation of plasticity after a critical elastic displacement of the elastic foundation. The formulation of our model is such that $\delta_{0}$ is a direct function of the stiffness $k$ of the elastic foundation and the yield stress $\sigma_{Y}$, i.e., $\delta_{0}=-\sigma_{Y} / k$. The critical displacement $\delta_{c}$ at the tip of the sill $(r=a)$ marks the failure of the host rock. The volume boundary condition and the two critical displacement boundary conditions write the following:

$$
\begin{gathered}
\delta_{c}=w_{1}(a)=\frac{\left(q_{0}-P_{0}\right) a^{4}}{64 D}+\frac{C_{1} a^{2}}{4}+C_{2}, \\
\delta_{0}=-\sigma_{Y} / k=w_{p}(b)=\frac{\left(q_{0}+\sigma_{Y}\right) b^{4}}{64 D}+\frac{C_{3} b^{2}}{4}+C_{4}+C_{5} \ln \left(\frac{b}{a}\right)+C_{6} b^{2} \ln \left(\frac{b}{a}\right),
\end{gathered}
$$




$$
V(a, b, \Delta P)=-2 \pi\left(\frac{\left(q_{0}-P_{0}\right) a^{6}}{384 D}+\frac{C_{1} a^{4}}{16}+\frac{C_{2} a^{2}}{2}-\frac{q_{0} a^{2}}{2 k}\right),
$$

with $C_{1}-C_{6}$ being complicated functions of $\Delta P, a$, and $b$. Equations (34)-(36) define a system of three equations with three unknowns, $\Delta P, a$, and $b$, which means that for any values of $\delta_{c^{\prime}} \sigma_{Y} / k$ and $V$, it is possible to calculate numerically a unique set of values of $\Delta P, a$, and $b$.

If we consider a growing intrusion with volume increasing linearly in time as $V(t)=Q t$, and constant propagation criteria $\delta_{c}$ and $\delta_{0}$, it is possible to calculate the evolution of $\Delta P, a$, and $b$ as a function of time by solving the system of equations (34) - (36), similarly to the analysis of Kerr and Pollard [1998] and Galland and Scheibert [2013].

Figure 8 displays the evolutions of $\Delta P, a$, and $\epsilon=(b-a) / a$ during the propagation of sills for various combinations of depth $h$, foundation yield stress $\sigma_{Y}$, and foundation stiffness $k$. In log-log plots, the simulations exhibit all the same scaling. For example, we can easily show that $a \propto V^{1 / 4}$ (see Figure 8a) and $\Delta P \propto V^{-1 / 2}$ (see Figure 8b). These scaling relations are the same as those found by Murdoch [2002] in the clamped elastic model and by Galland and Scheibert [2013] in an elastic model with an elastic foundation. Such similarity likely results from the fact that in our simulations using geological values, $a / I_{e} \ll 1$, i.e., the behavior of the system is dominated by the bending plate and not by the elastic foundation [Galland and Scheibert, 2013]. More interestingly, our results show that $\epsilon \propto V^{-1 / 4}$; i.e., the size of the plastic zone relative to the radius of the sill decreases during the propagation of the sill. Note, however, that the absolute size of the plastic zone is predicted to be constant $\left(I_{p}=\epsilon a \sim V^{-1 / 4} V^{1 / 4} \sim\right.$ constant $)$, i.e., it does not depend on the radius of the propagating sill.

Figure $8 \mathrm{c}$ shows that the values of $\epsilon$, for geologically relevant values of the model parameters, are all very small, with $I_{p}$ being typically smaller than $a / 100$. This confirms that the horizontal extent of the plastic zone is confined in the close vicinity of the intrusion's tip. Figure $8 \mathrm{c}$ also shows that $\epsilon$ greatly vary when $h, \sigma_{Y}$ and $k$ vary. Nevertheless, each curve of Figure $8 c$ follows a function of the form $\epsilon=\alpha V^{-1 / 4}$. Here, comparing the values of $\alpha$ between the curves is equivalent to comparing the relative values of $\epsilon$. Figure 9 displays the values of $\alpha$ calculated from the data plotted in Figure $8 \mathrm{c}$ as functions of the variable parameters $h, k$ and $\sigma_{Y}$. Each curve of each graph of Figure 9 displays the dependency of $\alpha$ with respect to one variable, the two others being constant. Figure 9a shows that $\alpha$ overall slightly decreases with increasing $h$, which shows that plastic zones are smaller for deeper sills. This result suggests that confinement at depth limits the development of plastic deformation. This conclusion, however, may lose validity for large values of $\sigma_{Y}$ (see Figure $9 \mathrm{a}$ ). Figure $9 \mathrm{~b}$ shows a stronger dependency of $\alpha$ with respect to $k$ : the larger $k$, the smaller $\alpha$. This is an intuitive result, which suggests that a stiff elastoplastic foundation localizes the plastic deformation to a small plastic zone, and conversely weak foundations enhance the development of a broad plastic zone. Finally, Figure $9 \mathrm{c}$ shows that $\alpha$ increases when the yield stress increases.

\section{Interpretation and Discussion}

\subsection{Model Validity}

The present model is a first attempt to include plasticity in analytic descriptions of sills and laccoliths. The model was kept simple on purpose, to make the analytical and numerical solutions tractable while still reflecting the overall features of the modeled systems. It exhibits the same limitations as most previous elastic models [Bunger and Cruden, 2011; Michaut, 2011; Galland and Scheibert, 2013; Michaut and Manga, 2014; Thorey and Michaut, 2014; Michaut et al., 2016], including linear elasticity of the deforming layer, the thin plate approximation, a single strata of homogeneous thickness, rigidity of the basement, and axisymmetric intrusions. Field observations and geophysical data show that sills and laccoliths exhibit overall subcircular shapes in planar view, even if they are never perfectly circular. Therefore, we consider our axisymmetric formulation to be relevant for addressing the main aspects of natural intrusions. In sedimentary basins, sills and laccoliths are dominantly emplaced in undeformed, flat-lying sedimentary layers. Therefore, we consider that homogeneous thickness of the overburden is a relevant assumption for intrusions in sedimentary basins. In contrast, in active volcanoes, topography is rarely flat; therefore, our model might have less implications for intrusions in such context.

A strong assumption of our model is the thin plate approximation, which implies that our model applies in a strict sense only to shallow intrusions that fulfill the condition $a>5 h$. Pollard and Johnson [1973] first 
argued that a single bending plate above sills and laccoliths is not relevant, given that their overburden is often made of stacks of sedimentary strata with different mechanical properties. They also argued that the frictional stresses between layers is most presumably much smaller than the bending stresses, so that the layers can be assumed to slide almost freely on one another. In these conditions, instead of using a single plate as thick as the intrusion's overburden, it is possible to split the overburden in many thinner plates. Doing so, the total stiffness $D$ of the layer stack is the sum of the stiffnesses $D_{i}$ of all layers [Pollard and Johnson, 1973], which is always smaller than $D$. Equivalently, the stiffness of a stack of layers of total thickness $h$ has the same stiffness as a single layer with a thickness smaller than $h$. To get a sense of the implications of the layering of the bending stack of layers, let us consider a stack of $N$ layers that have approximatively the same mechanical properties and the same thickness $h_{i}=h / N$. The equivalent thickness of the stack, i.e., the thickness of the single layer having the same bending stiffness, is $h_{e}=N^{1 / 3} h_{i}$. If we consider an $h=1000 \mathrm{~m}$ thick overburden made of $N=10$ layers, this means that the equivalent thickness is about $200 \mathrm{~m}$. In other words, the stack of layers is equivalent to a single layer, with a thickness $h_{e}$ five times smaller than the actual thickness $h$ of the stack. For $N=100, h_{e}$ becomes about 20 times smaller than the actual thickness. In summary, the thin plate approximation is valid when $a \gg h_{e}$, which considerably expands the domain of validity of our model, including sills and laccoliths with a radius $a$ possibly smaller than the depth $h$. Note that even when the layers are not identical, these conclusions remain qualitatively valid. They have been successfully applied to sills in the literature, e.g., the Henry mountains in Pollard and Johnson [1973] and Koch et al. [1981] or the High Himalaya in Scaillet et al. [1995].

The main difference between our model and former models is the introduction of a nonlinear behavior of the interfacial layer which connects the basement and the bending strata. We have implemented the two simplest plastic laws, namely rigid-perfectly plastic (section 2 ) and elastic-perfectly plastic (section 3 ). Both of them correspond to known analytical solutions for the axisymmetric bending layer problem, within the plastic zone. Any other behavior law based on a piecewise combination of constant and/or linear (with positive stiffness) laws as a function of vertical displacement could be used. These include elastic-plastic laws with strain hardening [Jaeger et al., 2009], as used in, e.g., Mazzini et al. [2009]. One would simply need to repeat the same procedure described here, i.e., write down the general solution for each region, apply the correct boundary conditions and solve the corresponding linear system of equations. Note that such nonlinear behavior laws can also be interpreted in the framework of cohesive zone models in fracture mechanics [Dugdale, 1960; Barenblatt, 1962], as previously noted by, e.g., Rubin [1993] and Chen et al. [2009].

We emphasize that the simple scaling of equation (14) is valid only for $\epsilon \ll 1$, i.e., when the plastic zone is small with respect to the radius of the intrusion. Such scaling might be lost when $\epsilon$ becomes large. Note as well that the values of $a / I_{e}$ in the propagation results calculated from the model with elastoplastic foundation (Figure 8) range between 24 and 980. Galland and Scheibert [2013] showed that for such values of $a / I_{e} \gg 1$, the behavior of the model with elastic foundation is dominated by the bending plate. The results and scaling calculated from the model developed in this paper (Figure 8) are thus valid under both approximations $\epsilon \ll 1$ and $a / l_{e} \gg 1$, which are dominantly fulfilled in natural systems. Our model might exhibit much more complex behavior if one or both approximations are not fulfilled (see, for example, the scaling of the model of Galland and Scheibert [2013] for $a / I_{e}<1$ ). Unraveling the full behavior of our model in a systematic manner would require extensive work, which extends beyond the scope of this paper.

In our model, like in all sill and laccolith models using the thin plate formulation [e.g., Pollard and Johnson, 1973; Kerr and Pollard, 1998; Murdoch, 2002; Bunger and Cruden, 2011; Galland and Scheibert, 2013], the overlying bending plate is considered purely elastic. Recent seismic [Hansen and Cartwright, 2006; Jackson et al., 2013; Magee et al., 2013] and geological [Agirrezabala, 2015] observations, however, show that substantial parts of deformation in sills' and laccoliths' overburden is accommodated by inelastic deformations (e.g., compaction and fluidization) in the bulk of the bending plate. Addressing such process would require further developments of our model.

In our model, we defined a tensile propagation criterion, similarly to existing theoretical and numerical models of sill and laccolith emplacement [Pollard and Johnson, 1973; Bunger and Cruden, 2011; Michaut, 2011; Galland and Scheibert, 2013; Michaut and Manga, 2014; Thorey and Michaut, 2014; Michaut et al., 2016]. Note, however, that geological observations evidence some compressional deformation accommodating the propagation of sill and laccolith tips [Pollard, 1973; Rubin, 1993; Spacapan et al., 2016, and references therein]. Accounting for 

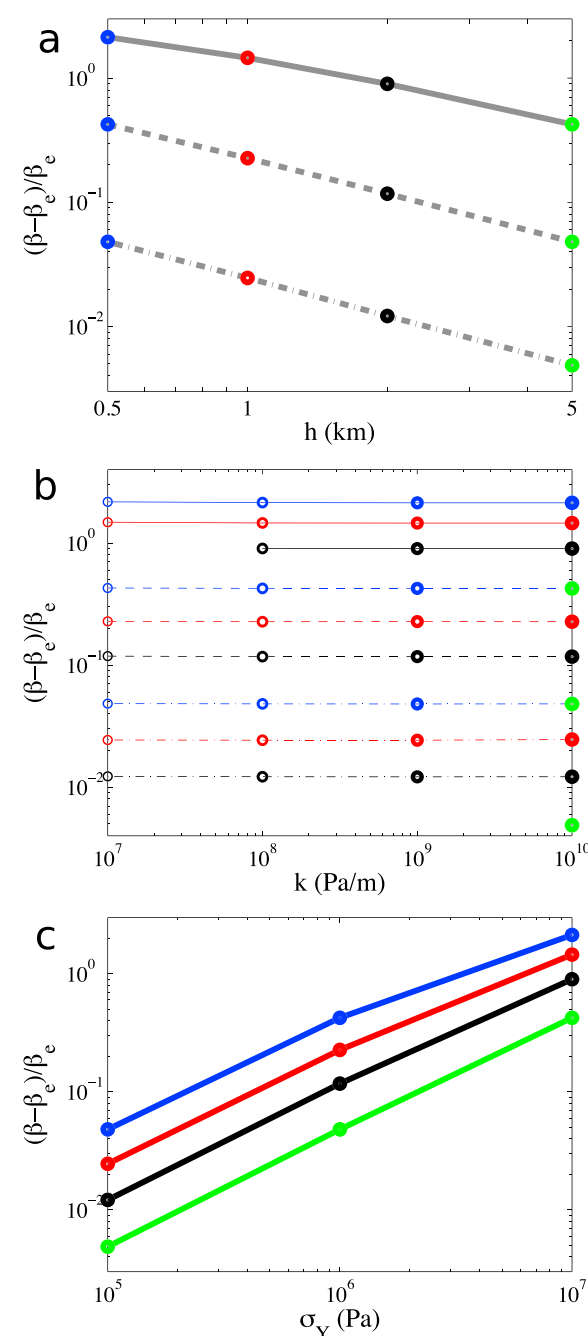

Legend

h (colors)

$-0.5 \mathrm{~km}$

$-1 \mathrm{~km}$

$-2 \mathrm{~km}$

$-\odot \mathrm{km}$

k (line width)

- $10^{7} \mathrm{~Pa} / \mathrm{m}$

- $10^{8} \mathrm{~Pa} / \mathrm{m}$

- $10^{9} \mathrm{~Pa} / \mathrm{m}$

- $10^{10} \mathrm{~Pa} / \mathrm{m}$

$\sigma_{\mathrm{y}}$ (line style)

-. $10^{5} \mathrm{~Pa}$

$-10^{6} \mathrm{~Pa}$

$-10^{7} \mathrm{~Pa}$

Figure 10. Relative difference of $\beta$ (defined as $\Delta P=\beta V^{-\frac{1}{2}}$ and calculated from data plotted in Figure 8b) between the elastoplastic (this work) and the purely elastic [Galland and Scheibert, 2013]) models, as a function of (a) the depth (h), (b) the stiffness of the elastic foundation $(k)$, and $(c)$ the yield stress of the elastic foundation $\left(\sigma_{Y}\right)$. Each curve of each plot considers only one variable parameter. Model parameters vary as follows: $h=0.5 \mathrm{~km}$ (blue), $h=1 \mathrm{~km}$ (red), $h=2 \mathrm{~km}$ (black), $h=5 \mathrm{~km}$ (green), $k=10^{7} \mathrm{~Pa} \mathrm{~m}^{-1}$ (thinnest line), $k=10^{8} \mathrm{~Pa} \mathrm{~m}^{-1}$ (second thinnest line), $k=10^{9} \mathrm{~Pa} \mathrm{~m}^{-1}$ (second thickest line), $k=10^{10} \mathrm{~Pa} \mathrm{~m}^{-1}$ (thickest line), $\sigma_{Y}=10^{5} \mathrm{~Pa}$ (dash-dotted line), $\sigma_{Y}=10^{6} \mathrm{~Pa}$ (dashed line), and $\sigma_{Y}=10^{7} \mathrm{~Pa}$ (solid line). Here $\delta_{c}=5 \delta_{0}$, where $\delta_{0}=-\sigma_{Y} / k$.

this local compression in our model would require the definition of a new propagation criterion; however, to our knowledge, such complex mechanical propagation criteria have not been discussed in the literature.

For sill propagation modeling purposes, we introduced a fracture criterion in terms of a critical vertical displacement $\left(\delta_{c}\right)$ of the bending layer with respect to its unstressed state. In the literature, this critical displacement $\delta_{c}$ is related to the fracture energy $G_{c}$ of the material (see, e.g., Scholz [2002, p.31] for a table of $G_{c}$ values for rocks): $G_{c}$ is the area under the stress-displacement curve for the interfacial material (Figures $2 b$ and $5 \mathrm{~b}$ ). In our models, $\delta_{c}=\frac{G_{c}}{\sigma_{Y}}$ for the rigid-perfectly plastic case used in section 2 and $\delta_{c}=\frac{G_{c}+\frac{\sigma_{Y}^{2}}{2 k}}{\sigma_{Y}}$ for the elastic-perfectly plastic case used in section 3.

\subsection{Geological Implications}

A first, key question that we can ask is whether the simple, appealing scaling for $\epsilon$ in equation (14) derived from the clamped model (section 2 ) is also valid for the more advanced model with elastoplastic foundation (section 3). To address this question, we replace $a$ and $\Delta P$ in equation (14) by their respective scaling $a \propto V^{1 / 4}$ and $\Delta P \propto V^{-1 / 2}$ observed during propagation within the elastoplastic model (Figures $8 \mathrm{a}$ and $8 \mathrm{~b}$ ). This yields 
$\epsilon \propto V^{-1 / 4}$, which is indeed the propagation behavior observed in Figure 8c. The scaling of equation (14) can therefore be considered as a fundamental scaling relation for the size of the plastic zone with respect to the intrusion radius and magma overpressure, with a wide applicability. This result implies that the relative size of the plastic zone, $\epsilon$, decreases with increasing radius of the intrusion. This conclusion is corroborated by the field observations of Pollard et al. [1975], Duffield et al. [1986], Schofield et al. [2012, 2014], and Spacapan et al. [2016], which provide evidence that plastic zones at the vicinity of the tips of small sills are sometimes as large as the sills themselves. In particular, Spacapan et al. [2016] compare the extent of inelastic deformation at the tips of intrusions of distinct radii. These authors suggest that the relative size of the inelastic zone decreases with the lengthening of the intrusions. Such conclusion is in very good agreement with the scaling of equation (14) and our results displayed in Figure 8c. Unfortunately, since our model formulation is based on the thin plate approximation, we cannot model arbitrarily small sills and thus the very first stages of sill propagation. However, constraining the mechanics of early sill can be very helpful to constrain the dynamics of sill initiation, as demonstrated by Kavanagh et al. [2015]. Those authors show that complex processes occur at sill inception and early growth, suggesting that plasticity might be crucial during this early stage of emplacement. Properly assessing the influence of plasticity on early sill propagation would require a different model formulation, e.g., the thick plate formulation [see, e.g., Panc, 1975] or finite element modeling.

A second practically important question is whether the existence of inelastic processes at the tip really affect the growth dynamics of the intrusion, irrespective of the actual size of the inelastic zone. To address this question, we compared the propagation dynamics of the model with elastoplastic foundation (this work) with that of the model with purely elastic foundation [Galland and Scheibert, 2013]. We already mentioned in the description of Figure 8 that the scalings of the sill's radius, $a$, and the overpressure, $\Delta P$, with the intrusion's volume, $V$, are identical for both models. The only difference is thus in the value of the prefactors of these relationships. We therefore define $\beta$ as the prefactor in $\Delta P=\beta V^{-1 / 2}$ for the elastoplastic model. $\beta$ is obtained by fitting the data in Figure $8 \mathrm{~b}$. We define $\beta_{e}$ in the same way for the elastic model. Figure 10 shows how the relative difference, $\frac{\beta-\beta_{e}}{\beta_{e}}$, between the two models, varies as a function of the model parameters $h, k$, and $\sigma_{Y}$. The differences observed range from less than $1 \%$ to as large as $200 \%$, meaning that the overpressure required to propagate the sill can be up to twice the value in the case of a purely elastic behavior of the system. Those large differences indicate that, depending on the conditions, the effect of the (although small) plastic zone can have a major influence on the propagation dynamics of sills and laccoliths. More precisely, differences are found larger for shallower intrusions (Figure 10a) or higher values of the yield stress of the interfacial layer in which the intrusion grows (Figure 10c). Those results can be qualitatively understood by comparing the lithostatic stress, which increases with $h$, and the plastic stress $\sigma_{Y}$ : large $h$ and/or small $\sigma_{Y}$ correspond to negligible plastic stress compared to the lithostatic stress. This limit precisely corresponds to the purely elastic model, and indeed, the differences tend to vanish. In contrast, the stiffness of the layer has negligible effect on propagation (Figure 10b). Note that we have performed the same analysis on the prefactor $\gamma$ of the relationship $a=\gamma V^{1 / 4}$ : the relative differences observed are found 1 order of magnitude smaller than those for $\beta$, for all parameters explored. The maximum observed difference of about $20 \%$ indicates that the relationship between the sill's radius and its volume is rather insensitive to the presence of plastic deformations at the intrusion's tip.

\section{Conclusions}

In this paper we develop and use an elastoplastic theoretical model of sill and laccolith emplacement. As in existing models, we use the formulation of a thin bending plate lying on a deformable elastic foundation. The novelty of the present study is the introduction of a cohesive plastic zone at the tip of the intrusion. The main results of our study are summarized below.

We first extended the classic clamped elastic model of Pollard and Johnson [1973] and derived a fully analytic model that includes a plastic zone at the intrusion's tip. This model involves a new characteristic length: the size of the plastic zone $\left(I_{p}\right)$. We define $\epsilon=I_{p} / a$, with $a$ the radius of the intrusion. The maximum uplift calculated with this model increases when $\epsilon$ increases and/or when the yield stress in the plastic zone $\left(\sigma_{Y}\right)$ decreases. The model is physically meaningful only for relatively small values of $\epsilon$, but this is the range that is relevant for geological observations.

We derived a simple scaling relation for the relative size $(\epsilon)$ of the plastic zone from the extended clamped model (equation (14)), which shows that $\epsilon$ scales (i) as $1 / a^{2}$, i.e., it is inversely proportional to the square of the 
intrusion's radius (a), and (ii) as $1 / \sqrt{\Delta P}$, i.e., it is inversely proportional to the square root of the overpressure within the intrusion.

We demonstrate that the clamped model with plastic zone is not suitable for modeling the dynamics of sill propagation. We thus implemented an elastoplastic foundation, an extension of the models of Kerr and Pollard [1998] and Galland and Scheibert [2013]. The predicted uplift is not significantly different from that predicted with the model of Pollard and Johnson [1973]. The most interesting outcome of the model is rather its ability to predict the evolution of the extent of the plastic zone during intrusion propagation. Using this latter model together with a critical displacement-based propagation criterion, we show that $\epsilon$ scales with the sill's volume as $V^{-1 / 4}$, i.e., the relative size of the plastic zone decreases during sill propagation. This conclusion was obtained when both approximations $\epsilon \ll 1$ and $a / I_{e} \gg 1$ are fulfilled.

Our model shows that the development of a plastic zone is limited due to confinement $(\epsilon$ decreases when $h$ increases), while it is enhanced when the host rock is more compliant ( $\epsilon$ decreases when $k$ increases).

We show that the simple scaling relation of equation (14), derived from the clamped plastic model, is also valid for the more advanced model with elastoplastic foundation. This scaling relation is thus a fundamental characteristic of the plastic zone with respect to the intrusion radius $(a)$ and magma overpressure $(\Delta P)$.

All in all, our novel elastoplastic model highlights that although the inelastic zone is probably negligibly small for the large, shallow sills considered here, it can have a significant effect on their propagation dynamics. We suggest that an interesting follow-up of this study would be to extend theoretical models beyond the thin plate approximation to also unravel the dynamics of early sill emplacement.

\section{Appendix A: Clamped Model}

Here we rewrite equations (7)-(12) for the clamped plastic model, combine them in matrix form used to calculate the solution for the six coefficients $C_{1}$ to $C_{6}$.

Using the expression of $w_{p}$ given in equation (6) and taken in $r=b$, equation (7) can be rewritten as

$$
\frac{\left(q_{0}+\sigma_{Y}\right) b^{4}}{64 D}+\frac{C_{3} b^{2}}{4}+C_{4}=0
$$

Using the derivative of equation (6) taken in $r=b$, equation (8) can be rewritten as

$$
\frac{\left(q_{0}+\sigma_{Y}\right) b^{3}}{16 D}+\frac{C_{3} b}{2}+\frac{C_{5}}{b}+C_{6} b=0
$$

Using the expressions of $w_{1}$ and $w_{p}$ given in equations (5) and (6) and taken in $r=a$, equation (9) can be rewritten as

$$
\frac{\left(q_{0}-P_{0}\right) a^{4}}{64 D}+\frac{C_{1} a^{2}}{4}+C_{2}+\frac{\left(P_{0}-P_{a}\right) a^{4}}{D(n+2)^{2}(n+4)^{2}}=\frac{\left(q_{0}+\sigma_{Y}\right) a^{4}}{64 D}+\frac{C_{3} a^{2}}{4}+C_{4}+C_{5} \ln \left(\frac{a}{b}\right)+C_{6} a^{2} \ln \left(\frac{a}{b}\right) .
$$

Using the first derivatives of equations (5) and (6) taken in $r=a$, equation (10) can be rewritten as

$$
\frac{\left(q_{0}-P_{0}\right) a^{3}}{16 D}+\frac{C_{1} a}{2}+\frac{\left(P_{0}-P_{a}\right) a^{3}}{D(n+2)^{2}(n+4)}=\frac{\left(q_{0}+\sigma_{Y}\right) a^{3}}{16 D}+\frac{C_{3} a}{2}+\frac{C_{5}}{a}+C_{6} a\left(1+2 \ln \left(\frac{a}{b}\right)\right) .
$$

Using the second derivatives of equations (5) and (6) taken in $r=a$, equation (11) can be rewritten as

$$
\frac{3\left(q_{0}-P_{0}\right) a^{2}}{16 D}+\frac{C_{1}}{2}+\frac{\left(P_{0}-P_{a}\right) a^{2}(n+3)}{D(n+2)^{2}(n+4)}=\frac{3\left(q_{0}+\sigma_{Y}\right) a^{2}}{16 D}+\frac{C_{3}}{2}-\frac{C_{5}}{a^{2}}+C_{6}\left(3+2 \ln \left(\frac{a}{b}\right)\right) .
$$

Using the third derivatives of equations (5) and (6) taken in $r=a$, equation (12) can be rewritten as

$$
\frac{3\left(q_{0}-P_{0}\right) a}{8 D}+\frac{\left(P_{0}-P_{a}\right) a(n+3)}{D(n+2)(n+4)}=\frac{3\left(q_{0}+\sigma_{Y}\right) a}{8 D}+\frac{2 C_{5}}{a^{3}}+\frac{2 C_{6}}{a}
$$

These equations constitute a system of six coupled linear equations, which can be written matricially as

$$
\text { A.C }=B
$$


with

$$
\begin{aligned}
& A=\left(\begin{array}{cccccc}
0 & 0 & \frac{b^{2}}{4} & 1 & 0 & 0 \\
0 & 0 & \frac{b}{2} & 0 & \frac{1}{b} & b \\
\frac{a^{2}}{4} & 1 & -\frac{a^{2}}{4} & -1 & -\ln \left(\frac{a}{b}\right) & -a^{2} \ln \left(\frac{a}{b}\right) \\
\frac{a}{2} & 0 & -\frac{a}{2} & 0 & -\frac{1}{a} & -a\left(1+2 \ln \left(\frac{a}{b}\right)\right) \\
\frac{1}{2} & 0 & -\frac{1}{2} & 0 & \frac{1}{a^{2}} & -\left(3+2 \ln \left(\frac{a}{b}\right)\right) \\
0 & 0 & 0 & 0 & -\frac{2}{a^{3}} & -\frac{2}{a}
\end{array}\right), \\
& B=\left(\begin{array}{c}
-\frac{\left(q_{0}+\sigma_{Y}\right) b^{4}}{64 D} \\
-\frac{\left(q_{0}+\sigma_{Y}\right) b^{3}}{16 D} \\
{\left[\frac{\left(P_{0}+\sigma_{Y}\right)}{64}-\frac{\left(P_{0}-P_{a}\right)}{(n+2)^{2}(n+4)^{2}}\right] \frac{a^{4}}{D}} \\
{\left[\frac{\left(P_{0}+\sigma_{Y}\right)}{16}-\frac{\left(P_{0}-P_{a}\right)}{(n+2)^{2}(n+4)}\right] \frac{a^{3}}{D}} \\
{\left[\frac{3\left(P_{0}+\sigma_{Y}\right)}{16}-\frac{\left(P_{0}-P_{a}\right)(n+3)}{(n+2)^{2}(n+4)}\right] \frac{a^{2}}{D}} \\
{\left[\frac{3\left(P_{0}+\sigma_{Y}\right)}{8}-\frac{\left(P_{0}-P_{a}\right)(n+3)}{(n+2)(n+4)}\right] \frac{a}{D}}
\end{array}\right)
\end{aligned}
$$

and

$$
C=\left(\begin{array}{l}
C_{1} \\
C_{2} \\
C_{3} \\
C_{4} \\
C_{5} \\
C_{6}
\end{array}\right)
$$

The solution vector $C$ has an analytic solution which is given in the Mathematica notebook provided as supporting information. When considering the pressure distribution as constant $\left(P_{0}=P_{a}\right)$, the following simplified expressions for the coefficients $C_{1}-C_{6}$ can be obtained:

$$
\begin{gathered}
C_{1}=\frac{\left(\sigma_{Y}+P_{0}\right) a^{2}\left(a^{2}-4 b^{2} \ln \left(\frac{a}{b}\right)\right)-\left(q_{0}+\sigma_{Y}\right) b^{4}}{8 b^{2} D}, \\
C_{2}=\frac{\left(\sigma_{Y}+P_{0}\right)\left[3 a^{4}-4 a^{2} b^{2}-4 a^{4} \ln \left(\frac{a}{b}\right)\right]+\left(q_{0}+\sigma_{Y}\right) b^{4}}{64 D}, \\
C_{3}=\frac{\left(\sigma_{Y}+P_{0}\right) a^{2}\left(a^{2}+2 b^{2}\right)-\left(q_{0}+\sigma_{Y}\right) b^{4}}{8 b^{2} D}, \\
C_{4}=\frac{-2\left(\sigma_{Y}+P_{0}\right) a^{2}\left(a^{2}+2 b^{2}\right)+\left(q_{0}+\sigma_{Y}\right) b^{4}}{64 D}, \\
C_{5}=-\frac{\left(\sigma_{Y}+P_{0}\right) a^{4}}{16 D}, \\
C_{6}=-\frac{\left(\sigma_{Y}+P_{0}\right) a^{2}}{8 D} .
\end{gathered}
$$

These solutions allow us to obtain, for any set of system parameters $\left(h, E, v, \rho\right.$, and $\left.\sigma_{Y}\right)$ and for any control parameters $\left(a, b\right.$, and $\left.P_{0}\right)$, the analytical expression of the radial profile of vertical displacement $w(r)$ (see, e.g., Figure 3). 
We provide as supporting information a Matlab code (SGHClampedPlastic.m) which calculates $C_{1}-C_{6}$ for any set of parameters $\left(h, E, v, \rho, \sigma_{Y}, P_{a}, n, a, b\right.$, and $\left.P_{0}\right)$. We also provide the analytic expressions in a Mathematica notebook.

\section{Appendix B: Taylor Expansion of the Clamped Model}

We obtain the series expansion of $C_{1}$ and $C_{2}$ with respect to $\epsilon$, for small $\epsilon$, by replacing the expression of $b=a(1+\epsilon)$ in equations (A8) and (A9) and by combining the terms with the same power of $\epsilon$ :

$$
\begin{gathered}
C_{1}=\frac{a^{2}\left(P_{0}-q_{0}\right)}{8 D}+\frac{a^{2} \epsilon\left(P_{0}-q_{0}\right)}{4 D}+\frac{a^{2} \epsilon^{2}\left(P_{0}-q_{0}\right)}{8 D}-\frac{a^{2} \epsilon^{3}\left(P_{0}+\sigma_{Y}\right)}{3 D}+\frac{a^{2} \epsilon^{4}\left(P_{0}+\sigma_{Y}\right)}{2 D}+O\left(\epsilon^{5}\right), \\
C_{2}=\frac{a^{4}\left(q_{0}-P_{0}\right)}{64 D}+\frac{a^{4} \epsilon\left(q_{0}-P_{0}\right)}{16 D}+\frac{3 a^{4} \epsilon^{2}\left(q_{0}-P_{0}\right)}{32 D}+\frac{a^{4} \epsilon^{3}\left(P_{0}+3 q_{0}+4 \sigma_{Y}\right)}{48 D}+\frac{a^{4} \epsilon^{4}\left(q_{0}-P_{0}\right)}{64 D}+O\left(\epsilon^{5}\right) .
\end{gathered}
$$

Setting $r=0$ in equation (5) provides a straightforward expression of the maximum displacement $w_{\max }$ :

$$
w_{1}(0)=w_{\max }=C_{2}
$$

Combining equation (B3) with equation (B2) leads to an approximate expression of the maximum displacement $w_{\max }$ as a function of the model parameters and $\epsilon$ :

$$
w_{\max } \approx \frac{a^{4}\left(q_{0}-P_{0}\right)}{64 D}+\frac{a^{4} \epsilon\left(q_{0}-P_{0}\right)}{16 D}+\frac{3 a^{4} \epsilon^{2}\left(q_{0}-P_{0}\right)}{32 D}+\frac{a^{4} \epsilon^{3}\left(P_{0}+3 q_{0}+4 \sigma_{Y}\right)}{48 D}+\frac{a^{4} \epsilon^{4}\left(q_{0}-P_{0}\right)}{64 D}
$$

which, in dimensionless form, reads $-\frac{64 D w_{\max }}{\Delta P a^{4}} \approx 1+4 \epsilon+6 \epsilon^{2}-\frac{4}{3}\left[1+\frac{4\left(q_{0}+\sigma_{Y}\right)}{\Delta P}\right] \epsilon^{3}+\epsilon^{4}$. This expression captures the behaviors shown in Figure 4.

Similarly, setting $r=a$ in equation (5) provides a straightforward expression of the displacement at the intrusion tip $(r=a)$ :

$$
w_{1}(a)=\frac{\left(q_{0}-P_{0}\right) a^{4}}{64 D}+\frac{C_{1} a^{2}}{4}+C_{2}
$$

Using the expressions of $C_{1}$ and $C_{2}$ from equations (B1) and (B2) in equations (B5), we derive an approximate expression of the displacement at the tip of the intrusion $(r=a)$ :

$$
w_{1}(a) \approx \frac{a^{4} \epsilon^{2}\left(q_{0}-P_{0}\right)}{16 D}+\frac{3 a^{4} \epsilon^{3}\left(q_{0}-P_{0}\right)}{48 D}+\frac{a^{4} \epsilon^{4}\left(7 P_{0}+8 \sigma_{Y}+q_{0}\right)}{64 D} .
$$

Note that the effect of the yield stress $\sigma_{Y}$ on $w_{1}(a)$ appears only at the fourth order of $\epsilon$.

\section{Appendix C: Elastoplastic Model}

Here we rewrite equations (26)-(33) for the elastoplastic model, combine them in matrix form used to calculate the solution for the eight coefficients $C_{1}$ to $C_{8}$.

Using the expressions of $w_{1}$ and $w_{p}$ in equations (23) and (24) and taken in $r=a$, equations (26) can be rewritten as

$$
\frac{\left(q_{0}-P_{0}\right) a^{4}}{64 D}+\frac{C_{1} a^{2}}{4}+C_{2}+\frac{\left(P_{0}-P_{a}\right) a^{4}}{D(n+2)^{2}(n+4)^{2}}=\frac{\left(q_{0}+\sigma_{Y}\right) a^{4}}{64 D}+\frac{C_{3} a^{2}}{4}+C_{4}
$$

Using the first derivatives of equations (23) and (24) taken in $r=a$, equation (27) can be rewritten as

$$
\frac{\left(q_{0}-P_{0}\right) a^{3}}{16 D}+\frac{C_{1} a}{2}+\frac{\left(P_{0}-P_{a}\right) a^{3}}{D(n+2)^{2}(n+4)}=\frac{\left(q_{0}+\sigma_{Y}\right) a^{3}}{16 D}+\frac{C_{3} a}{2}+\frac{C_{5}}{a}+C_{6} a .
$$


Using the second derivatives of equations (23) and (24) taken in $r=a$, equation (28) can be rewritten as

$$
\frac{3\left(q_{0}-P_{0}\right) a^{2}}{16 D}+\frac{C_{1}}{2}+\frac{\left(P_{0}-P_{a}\right) a^{2}(n+3)}{D(n+2)^{2}(n+4)}=\frac{3\left(q_{0}+\sigma_{Y}\right) a^{2}}{16 D}+\frac{C_{3}}{2}-\frac{C_{5}}{a^{2}}+3 C_{6}
$$

Using the third derivatives of equations (23) and (24) taken in $r=a$, equation (29) can be rewritten as

$$
\frac{3\left(q_{0}-P_{0}\right) a}{8 D}+\frac{\left(P_{0}-P_{a}\right) a(n+3)}{D(n+2)(n+4)}=\frac{3\left(q_{0}+\sigma_{Y}\right) a}{8 D}+\frac{2 C_{5}}{a^{3}}+\frac{2 C_{6}}{a}
$$

Using the expressions of $w_{p}$ and $w_{2}$ in equations (24) and (25) and taken in $r=b$, equation (30) can be rewritten as

$$
\frac{\left(q_{0}+\sigma_{Y}\right) b^{4}}{64 D}+\frac{C_{3} b^{2}}{4}+C_{4}+C_{5} \ln \left(\frac{b}{a}\right)+C_{6} b^{2} \ln \left(\frac{b}{a}\right)=C_{7} k e i_{0}\left(\frac{b}{l_{e}}\right)+C_{8} k e r_{0}\left(\frac{b}{l_{e}}\right)+\frac{q_{0}}{k}
$$

Using the first derivatives of equations (24) and (25) taken in $r=b$, equation (31) can be rewritten as

$$
\begin{aligned}
\frac{\left(q_{0}+\sigma_{Y}\right) b^{3}}{16 D}+\frac{C_{3} b}{2}+\frac{C_{5}}{b}+C_{6} b\left(2 \ln \left(\frac{b}{a}\right)+1\right)= & \frac{C_{7}}{\sqrt{2} I_{e}}\left[\operatorname{kei}_{1}\left(\frac{b}{I_{e}}\right)-\operatorname{ker}_{1}\left(\frac{b}{I_{e}}\right)\right] \\
& +\frac{C_{8}}{\sqrt{2} I_{e}}\left[k e i_{1}\left(\frac{b}{I_{e}}\right)+\operatorname{ker}_{1}\left(\frac{b}{I_{e}}\right)\right] .
\end{aligned}
$$

Using the second derivatives of equations (24) and (25) taken in $r=b$, equation (32) can be rewritten as $\frac{3\left(q_{0}+\sigma_{Y}\right) b^{2}}{16 D}+\frac{C_{3}}{2}-\frac{C_{5}}{b^{2}}+C_{6}\left(2 \ln \left(\frac{b}{a}\right)+3\right)=\frac{C_{7}}{2 I_{e}^{2}}\left[k e r_{0}\left(\frac{b}{I_{e}}\right)-k e r_{2}\left(\frac{b}{I_{e}}\right)\right]+\frac{C_{8}}{2 l_{e}^{2}}\left[k e i_{2}\left(\frac{b}{I_{e}}\right)-k e i_{0}\left(\frac{b}{I_{e}}\right)\right]_{(\text {C7 })}$ Using the third derivatives of equations (24) and (25) taken in $r=b$, equation (33) can be rewritten as

$$
\begin{aligned}
\frac{3\left(q_{0}+\sigma_{Y}\right) b}{8 D}+\frac{2 C_{5}}{b^{3}}+\frac{2 C_{6}}{b}= & \frac{C_{7}}{4 \sqrt{2} / 3}\left[3 k e r_{1}\left(\frac{b}{I_{e}}\right)-\operatorname{ker}_{3}\left(\frac{b}{I_{e}}\right)+3 k e i_{1}\left(\frac{b}{I_{e}}\right)-k e i_{3}\left(\frac{b}{I_{e}}\right)\right] \\
& +\frac{C_{8}}{4 \sqrt{2} / I_{e}^{3}}\left[3 k e r_{1}\left(\frac{b}{I_{e}}\right)-k e r_{3}\left(\frac{b}{l_{e}}\right)-3 k e i_{1}\left(\frac{b}{I_{e}}\right)+k e i_{3}\left(\frac{b}{I_{e}}\right)\right] .
\end{aligned}
$$

These equations constitute a system of eight coupled linear equations, which can be written matricially as

$$
A . C=B
$$

with

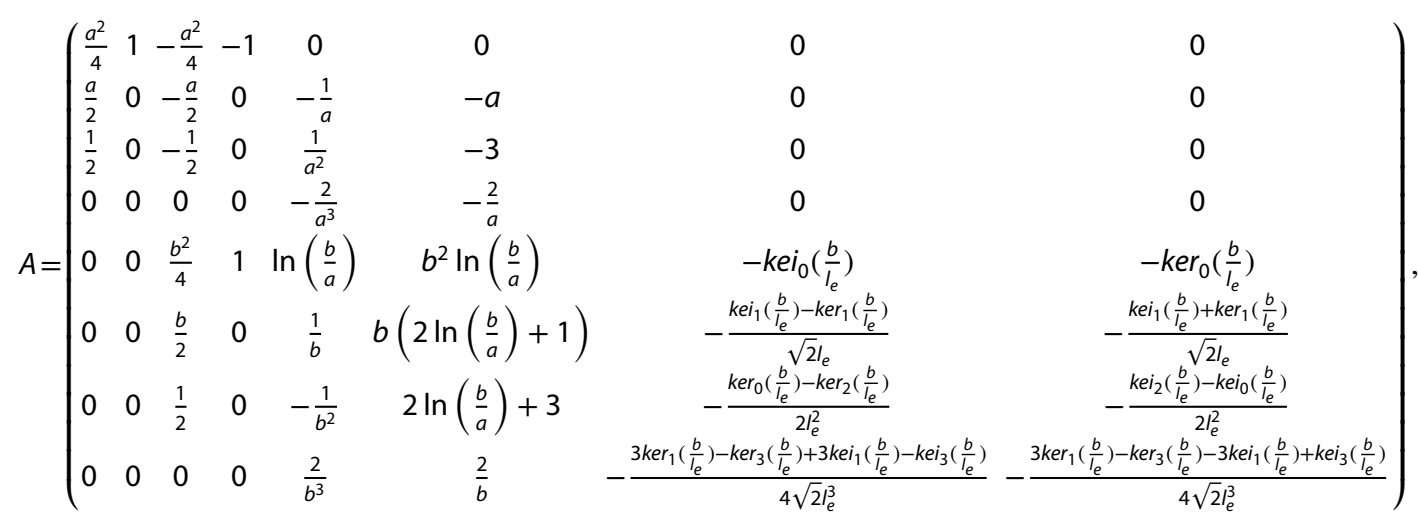




$$
B=\left(\begin{array}{c}
{\left[\frac{\left(P_{0}+\sigma_{Y}\right)}{64}-\frac{\left(P_{0}-P_{a}\right)}{(n+2)^{2}(n+4)^{2}}\right] \frac{a^{4}}{D}} \\
{\left[\frac{\left(P_{0}+\sigma_{Y}\right)}{16}-\frac{\left(P_{0}-P_{a}\right)}{(n+2)^{2}(n+4)}\right] \frac{a^{3}}{D}} \\
{\left[\frac{3\left(P_{0}+\sigma_{Y}\right)}{16}-\frac{\left(P_{0}-P_{a}\right)(n+3)}{(n+2)^{2}(n+4)}\right] \frac{a^{2}}{D}} \\
{\left[\frac{3\left(P_{0}+\sigma_{Y}\right)}{8}-\frac{\left(P_{0}-P_{a}\right)(n+3)}{(n+2)(n+4)}\right] \frac{a}{D}} \\
\frac{q_{0}}{k}-\frac{\left(q_{0}+\sigma_{Y} b^{4}\right.}{64 D} \\
-\frac{\left(q_{0}+\sigma_{Y}\right) b^{3}}{16 D} \\
-\frac{3\left(q_{0}+\sigma_{Y}\right) b^{2}}{16 D} \\
-\frac{3\left(q_{0}+\sigma_{Y}\right) b}{8 D}
\end{array}\right)
$$

and

$$
C=\left(\begin{array}{l}
C_{1} \\
C_{2} \\
C_{3} \\
C_{4} \\
C_{5} \\
C_{6} \\
C_{7} \\
C_{8}
\end{array}\right) .
$$

We provide as supporting information a Matlab code (SGHElastoPlastic.m) which calculates $C_{1}-C_{8}$ for any set of parameters $\left(h, E, v, \rho, \sigma_{Y}, k, P_{a}, n, a, b\right.$, and $\left.P_{0}\right)$.

\section{Appendix D: Approximate Expression for Maximum Uplift in the Elastoplastic Model}

For large values of the argument $x$, the asymptotic expressions of $k e i_{0}$ and $k e i_{0}$ are [see Timoshenko and Woinowsky-Krieger, 1959, p. 266, equation (j)]:

$$
\begin{aligned}
& \operatorname{ker}_{0}(x) \sim \sqrt{\frac{\pi}{2 x}} e^{-x / \sqrt{2}} \cos \left(\frac{x}{\sqrt{2}}+\frac{\pi}{8}\right) \\
& \operatorname{kei}_{0}(x) \sim-\sqrt{\frac{\pi}{2 x}} e^{-x / \sqrt{2}} \sin \left(\frac{x}{\sqrt{2}}+\frac{\pi}{8}\right)
\end{aligned}
$$

Defining $m=\frac{b}{l_{e} \sqrt{2}}$, the approximate analytical expression for the maximum uplift in the elastoplastic model, $w_{i, \max }$ is given by

Acknowledgments

The data for this paper are available by contacting the corresponding author at olivier.galland@geo.uio.no We also provide codes as supporting information to use the models described in this paper. This study was supported by Physics of Geological Processes (PGP). J.S. acknowledges support from the People Programme (Marie Curie Actions) of the European Union's 7th Framework Programme (FP7/2007-2013) under Research Executive Agency grant agreement 303871. This work was supported by the DIPS project (grant 240467) funded by the Norwegian Research Council. We gratefully acknowledge Thierry Menand and an anonymous reviewer for their constructive reviews.

$$
\begin{aligned}
& -\frac{64 D w_{i, \max }=}{a^{4}\left(P_{0}-q_{0}\right)}= \\
& \frac{4\left(P_{0}+\sigma_{Y}\right)}{\left(q_{0}-P_{0}\right)} \log \left(\frac{b}{a}\right)+\frac{q_{0}+\sigma_{Y}}{q_{0}-P_{0}} \frac{b^{4}\left(64 m^{4}+384 m^{3}+960 m^{2}+1440 m+945\right)}{a^{4}\left(64 m^{4}+128 m^{3}+64 m^{2}-15\right)}+ \\
& \frac{P_{0}+\sigma_{Y}}{q_{0}-P_{0}} \frac{a^{2}\left(192 m^{4}+640 m^{3}+576 m^{2}+160 m-45\right)-4 b^{2}\left(64 m^{4}+256 m^{3}+384 m^{2}+400 m+225\right)}{a^{2}\left(64 m^{4}+128 m^{3}+64 m^{2}-15\right)}
\end{aligned}
$$

\section{References}

Aarnes, I., K. Fristad, S. Planke, and H. Svensen (2011), The impact of host-rock composition on devolatilization of sedimentary rocks during contact metamorphism around mafic sheet intrusions, Geochem. Geophys. Geosyst., 12(10), Q10019, doi:10.1029/2011GC003636.

Agirrezabala, L. (2015), Syndepositional forced folding and related fluid plumbing above a magmatic laccolith: Insights from outcrop (Lower Cretaceous, Basque-Cantabrian basin, western Pyrenees), Geol. Soc. Am. Bull., 127(7-8), 982-1000, doi:10.1130/b31192.1.

Amelung, F., S. Jonsson, H. Zebker, and P. Segall (2000), Widespread uplift and "trapdoor" faulting on Galapagos volcanoes observed with radar interferometry, Nature, 407(6807), 993-996, doi:10.1038/35039604.

Barenblatt, G. (1962), The mathematical theory of equilibrium cracks in brittle fracture, Adv. Appl. Mech., 7, 55-129. 
Bunger, A. P. (2005), Near-surface hydraulic fracture, Phd thesis, Univ. of Minnesota.

Bunger, A. P., and A. R. Cruden (2011), Modeling the growth of laccoliths and large mafic sills: Role of magma body forces, J. Geophys. Res., 116, B02203, doi:10.1029/2010JB007648.

Burchardt, S. (2008), New insights into the mechanics of sill emplacement provided by field observations of the Njardvik sill, northeast Iceland, J. Volcanol. Geother. Res., 173(3-4), 280-288, doi:10.1016/j.jvolgeores.2008.02.009.

Chaput, M., V. Pinel, V. Famin, L. Michon, and J. Froger (2014), Cointrusive shear displacement by sill intrusion in a detachment: A numerical approach, Geophys. Res. Lett., 41(6), 1937-1943, doi:10.1002/2013GL058813.

Chen, Z., A. Bunger, X. Zhang, and R. Jeffrey (2009), Cohesive zone finite element-based modeling of hydraulic fractures, Acta Mech. Solida Sin., 22(5), 443-452, doi:10.1016/50894-9166(09)60295-0.

Chevallier, L., L. A. Gibson, L. O. Nhleko, A. C. Woodford, W. Nomquphu, and I. Kippie (2004), Hydrogeology of fractured-rock aquifers and related ecosystems within the Qoqodala dolerite ring and sill complex, Great Kei catchment, eastern Cape, Tech. Rep., 127 pp., Water Research Commission, South Africa.

Daniels, K. A., J. L. Kavanagh, T. Menand, and J. S. R. Stephen (2012), The shapes of dikes: Evidence for the influence of cooling and inelastic deformation, Geol. Soc. Am. Bull., 124(7-8), 1102-1112, doi:10.1130/b30537.1.

Delaney, P., and D. Pollard (1981), Deformation of Host Rocks and Flow of Magma During Growth of Minette Dikes and Breccia-Bearing Intrusions Near Ship Rock, New Mexico, U.S. Geological Survey professional paper 1202, 61 pp., Department of the Interior, Geological Survey, Washington, D. C.

Duffield, W. A., C. R. Bacon, and P. T. Delaney (1986), Deformation of poorly consolidated sediment during shallow emplacement of a basalt sill, Coso Range, California, Bull. Volcanol., 48(2), 97-107.

Dugdale, D. S. (1960), Yielding of steel sheets containing slits, J. Mech. Phys. Solids, 8(2), 100-104.

Fialko, Y., Y. Khazan, and M. Simons (2001), Deformation due to a pressurized horizontal circular crack in an elastic half space, with applications to volcano geodesy, Geophys. J. Int., 146(1), 181-190, doi:10.1046/j.1365-246X.2001.00452.x.

Galerne, C. Y., O. Galland, E.-R. Neumann, and S. Planke (2011), 3D relationships between sills and their feeders: Evidence from the Golden Valley Sill Complex (Karoo Basin) and experimental modelling, J. Volcanol. Geotherm. Res., 202(3-4), 189-199, doi:10.1016/j.jvolgeores.2011.02.006.

Galland, O. (2012), Experimental modelling of ground deformation associated with shallow magma intrusions, Earth Planet. Sci. Lett., 317-318, 145-156, doi:10.1016/j.epsl.2011.10.017.

Galland, O., and J. Scheibert (2013), Analytical model of surface uplift above axisymmetric flat-lying magma intrusions: Implications for sill emplacement and geodesy, J. Volcanol. Geotherm. Res., 253, 114-130, doi:10.1016/j.jvolgeores.2012.12.006.

Galland, O., S. Planke, E.-R. Neumann, and A. Malthe-Sørenssen (2009), Experimental modelling of shallow magma emplacement: Application to saucer-shaped intrusions, Earth Planet. Sci. Lett., 277(3-4), 373-383.

Galland, O., S. Burchardt, E. Hallot, R. Mourgues, and C. Bulois (2014), Dynamics of dikes versus cone sheets in volcanic systems, J. Geophys. Res., 119(8), 6178-6192, doi:10.1002/2014jb011059.

Goulty, N. R., and N. Schofield (2008), Implications of simple flexure theory for the formation of saucer-shaped sills, J. Struct. Geol., 30(7), 812-817.

Hansen, D., J. Cartwright, and D. Thomas (2004), 3D Seismic Analysis of the Geometry of Igneous Sills and Sill Junction Relationships, vol. 29, Geol. Soc. London Mem., London.

Hansen, D. M., and J. A. Cartwright (2006), The three-dimensional geometry and growth of forced folds above saucer-shaped igneous sills, J. Struct. Geol., 28(8), 1520-1535.

Hansen, D. M., J. Redfern, F. Federici, D. di Biase, and G. Bertozzi (2008), Miocene igneous activity in the Northern Subbasin, offshore Senegal, NW Africa, Mar. Pet. Geol., 25(1), 1-15.

Jackson, C., N. Schofield, and B. Golenkov (2013), Geometry and controls on the development of igneous sill-related forced-folds: A 2D seismic reflection case study from offshore southern Australia, Geol. Soc. Am. Bull., 125(11-12), 1874-1890.

Jackson, M. D., and D. D. Pollard (1990), Flexure and faulting of sedimentary host rocks during growth of igneous domes, Henry Mountains, Utah, J. Struct. Geol., 12(2), 185-206.

Jaeger, J., N. Cook, and R. Zimmerman (2009), Fundamentals of Rock Mechanics, 475 pp., Blackwell Publ. Ltd, Oxford.

Kavanagh, J., D. Boutelier, and A. Cruden (2015), The mechanics of sill inception, propagation and growth: Experimental evidence for rapid reduction in magmatic overpressure, Earth Planet. Sci. Lett., 421, 117-128, doi:10.1016/j.epsl.2015.03.038.

Kerr, A. D., and D. D. Pollard (1998), Toward more realistic formulations for the analysis of laccoliths, J. Struct. Geol., 20(12), 1783-1793.

Koch, F., A. Johnson, and D. Pollard (1981), Monoclinal bending of strata over laccolithic intrusions, Tectonophysics, 74(3), T21 - T31.

Magee, C., F. Briggs, and C. Jackson (2013), Lithological controls on igneous intrusion-induced ground deformation, J. Geol. Soc., 170(6), 853-856.

Magee, C., C. A. L. Jackson, and N. Schofield (2014), Diachronous sub-volcanic intrusion along deep-water margins: Insights from the Irish Rockall Basin, Basin Res., 26(1), 85-105, doi:10.1111/bre.12044.

Magee, C., et al. (2016), Lateral magma flow in mafic sill complexes, Geosphere, 12(3), 809-841, doi:10.1130/ges01256.1.

Malthe-Sørenssen, A., S. Planke, H. Svensen, and B. Jamtveit (2004), Formation of saucer-shaped sills, Geol. Soc. London Spec. Pub., 234, 215-227.

Mazzini, A., A. Nermoen, M. Krotkiewski, Y. Podladchikov, S. Planke, and H. Svensen (2009), Strike-slip faulting as a trigger mechanism for overpressure release through piercement structures. Implications for the Lusi Mud Volcano, Indonesia, Marine Petrol. Geol., 26(9), $1751-1765$.

Meriaux, C., J. R. Lister, V. Lyakhovsky, and A. Agnon (1999), Dyke propagation with distributed damage of the host rock, Earth Planet. Sci. Lett., 165(2), 177-185.

Michaut, C. (2011), Dynamics of magmatic intrusions in the upper crust: Theory and applications to laccoliths on Earth and the Moon, J. Geophys. Res., 116, B05205, doi:10.1029/2010JB008108.

Michaut, C., and M. Manga (2014), Domes, pits, and small chaos on Europa produced by water sills, J. Geophys. Res. Planets, 119(3), 550-573, doi:10.1002/2013je004558.

Michaut, C., M. Thiriet, and C. Thorey (2016), Insights into mare basalt thicknesses on the moon from intrusive magmatism, Phys. Earth Planet. Interiors, 257, 187-192, doi:10.1016/j.pepi.2016.05.019.

Mogi, K. (1958), Relations between the eruptions of various volcanoes and the deformations of the ground surface around them, Bull. Earthquake Res. Inst. Univ. Tokyo, 36, 99-134.

Murdoch, L. C. (2002), Mechanical analysis of idealized shallow hydraulic fracture, J. Geotech. Geoenviron. Eng., 128(6), 488-495.

Nobile, A., C. Pagli, D. Keir, T. Wright, A. Ayele, J. Ruch, and V. Acocella (2012), Dike-fault interaction during the 2004 Dallol intrusion at the northern edge of the Erta Ale ridge (Afar, Ethiopia), Geophys. Res. Lett., 39(19), L19305, doi:10.1029/2012GL053152. 
Okada, Y. (1985), Surface deformation due to shear and tensile faults in a half-space, Bull. Seism. Soc. Am., 75(4), $1135-1154$.

Pagli, C., T. Wright, C. Ebinger, S.-H. Yun, J. Cann, T. Barnie, and A. Ayele (2012), Shallow axial magma chamber at the slow-spreading Erta Ale ridge, Nature Geosci., 5(4), 284-288.

Panc, V. (1975), Theories of Elastic Plates, Noordhoff, Leyden, Prague.

Pasquare, F., and A. Tibaldi (2007), Structure of a sheet-laccolith system revealing the interplay between tectonic and magma stresses at Stardalur volcano, Iceland, J. Volcanol. Geotherm. Res., 161(1-2), 131-150.

Pedersen, R., and F. Sigmundsson (2004), InSAR based sill model links spatially offset areas of deformation and seismicity for the 1994 unrest episode at Eyjafjallajökull volcano, Iceland, Geophys. Res. Lett., 31(14), L14610, doi:10.1029/2004GL020368.

Pedersen, R., and F. Sigmundsson (2006), Temporal development of the 1999 intrusive episode in the Eyjafjallajökull volcano, Iceland, derived from InSAR images, Bull. Volcanol., 68(4), 377-393.

Petford, N., and K. McCaffrey (2003), Hydrocarbons in Crystalline Rocks, vol. 214, Geol. Soc. London Spec Pub., London.

Planke, S., T. Rasmussen, S. Rey, and R. Myklebust (2005), Seismic characteristics and distribution of volcanic intrusions and hydrothermal vent complexes in the Voring and More basins, in Proceedings of the 6th Petroleum Geology Conference, edited by A. G. Doro and B. A. Vining, pp. 833-844, Geological Society, London.

Pollard, D. (1973), Derivation and evaluation of a mechanical model for sheet intrusions, Tectonophysics, 19(3), $233-269$.

Pollard, D., O. Muller, and D. Dockstader (1975), The form and growth of fingered sheet intrusions, Geol. Soc. Am. Bull., 86(3), $351-363$.

Pollard, D. D., and A. M. Johnson (1973), Mechanics of growth of some laccolithic intrusions in the Henry Mountains, Utah: II. Bending and failure of overburden layers and sill formation, Tectonophysics, 18, 311-354.

Polteau, S., A. Mazzini, O. Galland, S. Planke, and A. Malthe-Sørenssen (2008), Saucer-shaped intrusions: Occurrences, emplacement and implications, Earth Planet. Sci. Lett., 266(1-2), 195-204.

Rivalta, E. (2010), Evidence that coupling to magma chambers controls the volume history and velocity of laterally propagating intrusions, J. Geophys. Res., 115, B07203, doi:10.1029/2009JB006922.

Rodriguez Monreal, F., H. J. Villar, R. Baudino, D. Delpino, and S. Zencich (2009), Modeling an atypical petroleum system: A case study of hydrocarbon generation, migration and accumulation related to igneous intrusions in the Neuqun Basin, Argentina, Marine Petrol. Geol., 26(4), 590-605, doi:10.1016/j.marpetgeo.2009.01.005.

Roman, D. C., and K. V. Cashman (2006), The origin of volcano-tectonics earthquake swarms, Geology, 34(6), 457-460.

Rubin, A. (1993), Tensile fracture of rock at high confining pressure: Implications for dike propagation, J. Geophys. Res., 98, $15919-15935$.

Scaillet, B., A. Pêcher, P. Rochette, and M. Champenois (1995), The Gangotri granite (Garhwal Himalaya): Laccolithic emplacement in an extending collisional belt, J. Geophys. Res., 100, 585-607.

Schofield, N., I. Alsop, J. Warren, J. Underhill, R. Lehne, W. Beer, and V. Lukas (2014), Mobilizing salt: Magma-salt interactions, Geology, 42(7), 599-602, doi:10.1130/G35406.1.

Schofield, N. J., D. J. Brown, C. Magee, and C. T. Stevenson (2012), Sill morphology and comparison of brittle and non-brittle emplacement mechanisms, J. Geol. Soc. London, 169(2), 127-141, doi:10.1144/0016-76492011-078.

Scholz, C. (2002), The Mechanics of Earthquakes and Faulting, 471 pp., Cambridge Univ. Press, Cambridge.

Schutter, S. R. (2003), Occurrences of hydrocarbons in and around igneous rocks, Geol. Soc. London Spec. Pub., 214(1), 35-68.

Senger, K., S. Buckley, L. Chevallier, A. Fagreng, O. Galland, T. Kurz, K. Ogata, S. Planke, and J. Tveranger (2015), Fracturing of doleritic intrusions and associated contact zones: Insights from the eastern Cape, South Africa, J. African Earth Sci., 102, 70-85.

Sigmundsson, F., et al. (2010), Intrusion triggering of the 2010 Eyjafjallajökull explosive eruption, Nature, 468(7322), 426-430.

Spacapan, J., O. Galland, H. A. Leanza, and S. Planke (2016), Igneous sill emplacement mechanism in shale-dominated formations: A field study at Cuesta del Chihuido, Neuqun Basin, Argentina, J. Geol. Soc., doi:10.1144/jgs2016-056.

Sun, R. J. (1969), Theoretical size of hydraulically induced horizontal fractures and corresponding surface uplift in an idealized medium, J. Geophys. Res., 74(25), 5995-6011.

Svensen, H., S. Planke, A. Malthe-Sørenssen, B. Jamtvelt, R. Myklebust, T. Eldem, and S. Rey (2004), Release of methane from a volcanic basin as a mechanism for initial eocene global warming, Nature, 429(6991), 542-545.

Thorey, C., and C. Michaut (2014), A model for the dynamics of crater-centered intrusion: Application to lunar floor-fractured craters, J. Geophys. Res.: Planets, 119(1), 286-312, doi:10.1002/2013JE004467.

Timoshenko, S., and S. Woinowsky-Krieger (1959), Theory of Plates and Shells, McGraw-Hill Book Company, New York.

Trude, J., J. Cartwright, R. Davies, and J. Smallwood (2003), New technique for dating igneous sills, Geology, 31(9), 813-816. 